\title{
Observed fingerprint of a weakening Atlantic Ocean overturning circulation
}

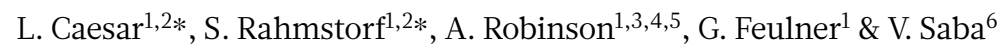

\begin{abstract}
The Atlantic meridional overturning circulation (AMOC) - a system of ocean currents in the North Atlantic-has a major impact on climate, yet its evolution during the industrial era is poorly known owing to a lack of direct current measurements. Here we provide evidence for a weakening of the AMOC by about $3 \pm 1$ sverdrups (around 15 per cent) since the mid-twentieth century. This weakening is revealed by a characteristic spatial and seasonal sea-surface temperature 'fingerprint' - consisting of a pattern of cooling in the subpolar Atlantic Ocean and warming in the Gulf Stream regionand is calibrated through an ensemble of model simulations from the CMIP5 project. We find this fingerprint both in a high-resolution climate model in response to increasing atmospheric carbon dioxide concentrations, and in the temperature trends observed since the late nineteenth century. The pattern can be explained by a slowdown in the AMOC and reduced northward heat transport, as well as an associated northward shift of the Gulf Stream. Comparisons with recent direct measurements from the RAPID project and several other studies provide a consistent depiction of recordlow AMOC values in recent years.
\end{abstract}

The AMOC is one of Earth's major ocean circulation systems, redistributing heat on our planet and thereby affecting its climate. At the same time, it is a highly nonlinear system with a critical threshold, depending on a delicate balance of temperature and salinity effects on density, and is considered one of the main tipping elements of the Earth system ${ }^{1,2}$. Changes in Atlantic overturning have been responsible for some of the strongest and most rapid climate shifts during the Quaternary Period (the past 2.6 million years) ${ }^{3}$. These historical changes in the AMOC have not only affected the North Atlantic and surrounding landmasses, but have also had global impacts. For example, a slowdown of the AMOC is associated with a southward shift of the tropical rainfall belt and a warming of the Southern Ocean and Antarctica (the 'see-saw' response) ${ }^{2,3}$.

Given the potentially disruptive impact of a major change in the $A M O C$, it is imperative to better understand whether and how the $\mathrm{AMOC}$ is responding to modern anthropogenic warming. Direct continuous measurements of the AMOC have only been available for a little over a decade and are therefore probably dominated by natural variability ${ }^{4}$. The longer-term evolution of the AMOC needs to be reconstructed from indirect indicators. Based on the observed cooling trend in the subpolar Atlantic since the early twentieth century, recent studies have suggested that the AMOC may have slowed over this period ${ }^{5-7}$. However, it has also been suggested that another mechanism could explain the subpolar Atlantic cooling, for example, the increasing aerosol load of the atmosphere . $^{8}$

Here we use the latest high-resolution climate model results to identify a characteristic sea-surface temperature (SST) fingerprint, consisting of a cooling in the subpolar gyre region and a warming in the Gulf Stream region, which in the climate model is associated with an $A M O C$ reduction in response to rising atmospheric carbon dioxide $\left(\mathrm{CO}_{2}\right)$ levels ${ }^{9}$. We then compare this fingerprint with the observed SST evolution since the late nineteenth century, including consideration of the seasonal cycle. We use the climate-model ensemble of the Coupled Model Intercomparison Project Phase 5 (CMIP5) to test and calibrate a revised $A M O C$ index, and we present a new reconstruction of the AMOC evolution for the period 1870 to 2016. This index reaches record-low values in the past few years and, for the periods of overlap, is consistent with direct measurements, reanalysis data of the AMOC since 1995 and other AMOC studies.

\section{Comparing climate model and SST observations}

We use the CM2.6 coupled global climate model, which provides high horizontal resolution of around $50 \mathrm{~km}$ in the atmosphere and $10 \mathrm{~km}$ in the ocean (see Methods). The latter is important for analysing SST data because high resolution helps to reduce regional SST biases ${ }^{10}$. The model resolves mesoscale ocean eddies ${ }^{11}$ and shows a more realistic simulation of the Gulf Stream relative to coarser model versions. In particular, this model practically eliminates a bias in the separation point of the Gulf Stream from the United States' coastline (leading to a warm and salty bias along the continental shelf), which is common in coarser climate models assessed by the Intergovernmental Panel on Climate Change (IPCC) $)^{9}$. After appropriate spin-up, we used two simulations: a control simulation of 80 years' duration with $\mathrm{CO}_{2}$ concentrations fixed at the 1860 level, and a run in which atmospheric $\mathrm{CO}_{2}$ increased by $1 \%$ per year over 70 years until it doubled, and then remained at this level for another 10 years.

Figure 1 shows the linear trend in SST over the ' $\mathrm{CO}_{2}$-doubling' experiment and the corresponding control run, compared with the observed trend from 1870 to 2016 (owing to the extreme computational costs of the CM2.6 model, neither a simulation with historic forcing nor ensemble studies are available). The trend pattern of the observed SSTs is not sensitive to the choice of the time interval used to calculate the linear trend (see Extended Data Fig. 1). Figure 1 shows that the control run is almost free of SST trends, and that the observed SST trend pattern resembles that measured in the $\mathrm{CO}_{2}$-doubling experiment. To account for the much larger global SST warming (by a factor of four) seen in the model experiment compared with observations, in Fig. 2 we divide both patterns by the global mean SST trend

${ }^{1}$ Potsdam Institute for Climate Impact Research (PIK), Potsdam, Germany. ${ }^{2}$ Institute of Physics and Astronomy, University of Potsdam, Potsdam, Germany. ${ }^{3}$ Complutense University of Madrid, Madrid, Spain. ${ }^{4}$ Instituto de Geociencias, CSIC-UCM, Madrid, Spain. ${ }^{5}$ National and Kapodistrian University of Athens, Athens, Greece. ${ }^{6}$ National Oceanic and Atmospheric Administration, National Marine Fisheries Service, Northeast Fisheries Science Center, Geophysical Fluid Dynamics Laboratory, Princeton University, Princeton, NJ, USA. *e-mail: caesar@pik-potsdam.de; stefan@pik-potsdam.de 


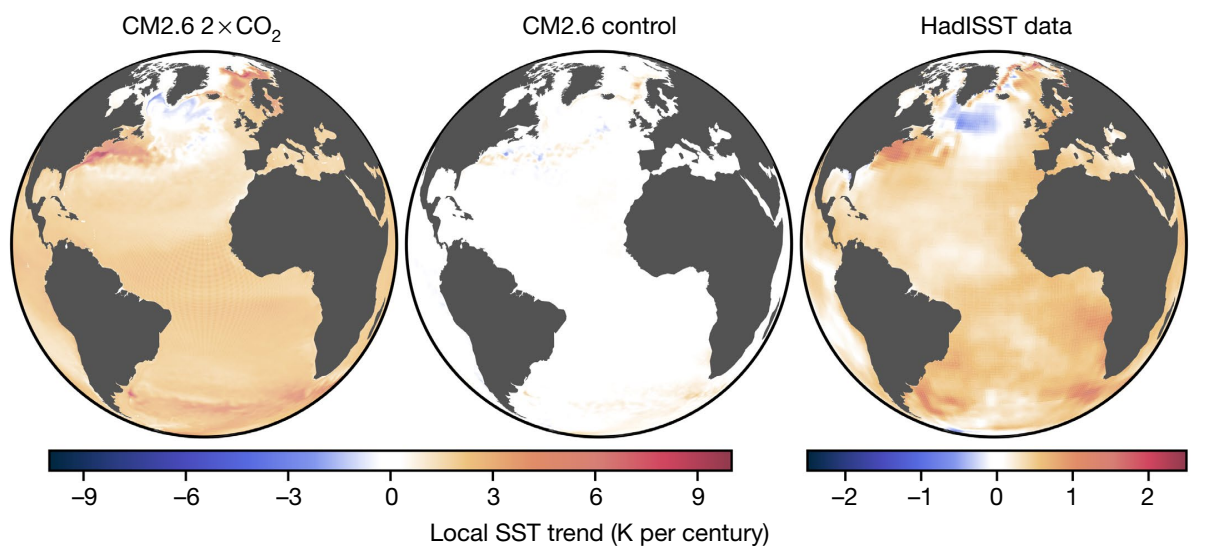

Fig. 1 | Comparison of SST trends in model and observations. Left and middle, linear SST trends obtained using the CM2.6 climate model of the Geophysical Fluid Dynamics Laboratory (GFDL) during a $\mathrm{CO}_{2}$-doubling experiment (left) and in a control run with fixed $\mathrm{CO}_{2}$ concentrations

to normalize the amplitude. A global view of these SST trends is shown in Extended Data Fig. 2.

The comparison of the normalized modelled and observed SST trend patterns (Fig. 2) shows a remarkable resemblance, especially when focusing on the northern Atlantic - the area where SSTs are most affected by changes in the AMOC. Both patterns comprise an area of below-average warming (normalized trend $<1$ ) and cooling (normalized trend $<0$ ) in the subpolar gyre region. This lack of warming or cooling is associated with a slowdown of the AMOC by around 4 sverdrups (Sv; $1 \mathrm{~Sv}=10^{6} \mathrm{~m}^{3} \mathrm{~s}^{-1}$ ) - as predicted by the CM2.6 simulation (see Fig. 3) - and a corresponding reduction in heat transport into that region. This feature is accompanied by an above-average warming (normalized trend $>1$ ) in the vicinity of the Gulf Stream, which is enhanced by up to a factor of four-five over the global mean warming (for a definition of the regions, see inset of Fig. 3). The median trend of the subpolar gyre region is located at the third percentile of all trends in the observational data, and at the first percentile in the model. The median trends in the Gulf Stream region are located at the 96th and 98th percentiles of all trends in the observational data and model, respectively (see Methods and Extended Data Fig. 3). We define the combination of these features as the AMOC fingerprint, as both signals can be physically linked to changes in the AMOC.

Although the cold patch in the subpolar gyre region has previously been connected to a slowdown of the $\mathrm{AMOC}^{7}$ and is present in the CMIP5 simulations ${ }^{12}$, here we are able to link the extreme warming observed along the US northeast coast to the Gulf Stream shifting northwards and closer to shore as a consequence of an AMOC slowdown (see Extended Data Fig. 4a). An opposite (that is, southward) Gulf Stream shift has previously been found as a response to an AMOC strengthening in idealized model simulations in which the AMOC was deliberately enhanced by an imposed density anomaly in the deep overflow from the Nordic Seas; this overflow feeds the lower branch of the $\mathrm{AMOC}^{13}$, the deep western boundary current (DWBC). The physical mechanism of the interaction of the DWBC with the Gulf Stream at their crossing point is a robust mechanism that is known from theory and from both conceptual and more complex models: it is a consequence of vorticity conservation on a rotating sphere ${ }^{14}$. The downslope flow of the DWBC in the crossover region leads to vortex stretching, which must be balanced higher up in the water column, leading to the formation of a northern recirculation gyre that forces the Gulf Stream to separate from the US east coast. As the flow of the DWBC is strengthened, the recirculation gyre becomes stronger and the separation point of the Gulf Stream moves southwards. Given that the Gulf Stream transports warm water, this signal is reflected in the SST. For a more detailed discussion of this mechanism, see Methods.

The physical mechanism behind the warming also explains why it cannot be seen in climate models with a coarser ocean resolution, (middle). Right, observed SST trends from 1870 to 2016 (HadISST data). We used data from the November-May season. Note the different scales related to the differing amounts of $\mathrm{CO}_{2}$ forcing between model and observations.

including versions that are similar to CM2.6, with the same atmosphere but a coarser ocean resolution. Only the high-resolution model accurately represents the formation of the northern recirculation gyre and thus the correct coastal separation position of the Gulf Stream, which is a necessary condition for modelling the shifts in the Gulf Stream that are due to changes in AMOC strength. The northward shift of the warm water of the Gulf Stream leads to extreme warming along the US coast and a cooling to the south of this warming (as can be seen by the blue area to the south of the Gulf Stream in the CM2.6 simulation; Fig. 2). Another indication of a northward shift of the Gulf Stream in the CM2.6 model is enhanced warming of ocean-bottom temperatures on the continental shelf, particularly in the Gulf of Maine, as a result of a poleward retreat of the Labrador Current following the northward shift ${ }^{9}$. This warm part of the AMOC fingerprint cannot be explained by aerosol shading. The cooling in the subpolar gyre region in the CM2.6 model cannot be caused by aerosols either, because the modelled response is entirely $\mathrm{CO}_{2}$-driven - that is, no aerosol forcing was prescribed. This strongly supports earlier arguments against the aerosol hypothesis ${ }^{15}$.

We have looked for the fingerprint of an AMOC slowdown in seven available observational SST data products (Extended Data Fig. 5). All of these datasets show the cold patch in the subpolar Atlantic, and, to a greater or lesser extent, the enhanced warming inshore of the Gulf Stream. The weaker cooling signal just south of this warming cannot be seen in most of the observational datasets (except the COBE data; see Extended Data Fig. 5). This could be because of the lower spatial resolution of the observational data products and the smaller AMOC decline in the observations as compared with the model simulation. The data products are distinct partly because of the different input databases used, and because of different degrees of data homogenization, bias adjustment, averaging and interpolation, which preserve different amounts of spatial and temporal structure (see Extended Data Table 1). The main difference is that, for example, the ERSST data concentrate on the preservation of temporal structure, whereas the HadISST data focus on the preservation of spatial structure. As we are interested in the spatial pattern of longer-term trends, in Fig. 2 we show the SST data with the best combination of spatial resolution (1.0 $\times 1.0$ degrees), spatial preservation and quality control, namely, the HadISST data ${ }^{16}$.

We note that the sea-ice-covered regions of the Arctic Ocean show no temperature trend, consistent with the assumption that SST remains close to freezing point there. In the observations, this blue area is crossed by a red line where the sea-ice margin has retreated (Fig. 2). The linkages of the AMOC in the open Atlantic to the northward flow of Atlantic waters past Iceland warrant further investigation, but are beyond the scope of this paper.

Finally, both model and data show widespread above-average warming in the South Atlantic, consistent with the temperature see-saw effect of an AMOC decline leading to reduced northward ocean heat 

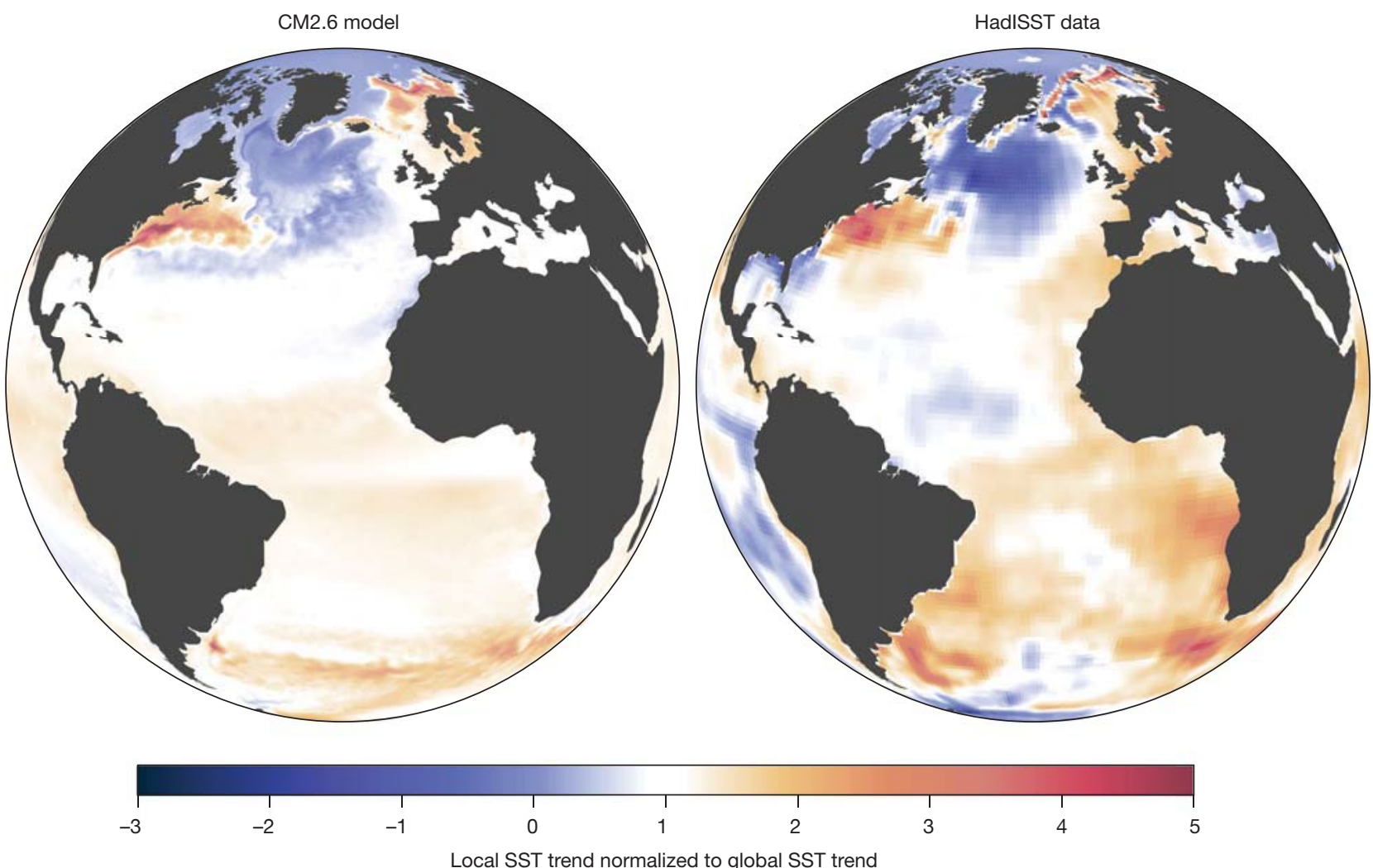

Fig. 2 Comparison of normalized SST trends. Left, linear SST trends during a $\mathrm{CO}_{2}$-doubling experiment using the GFDL CM2.6 climate model. Right, observed trends during 1870-2016 (HadISST data). Both sets of data are normalized with the respective global mean SST trends, and in both cases we used data from the November-May season. Regions that show cooling or below-average warming are shown in blue; regions that show above-average warming are in red. Owing to the much greater climate change in the $\mathrm{CO}_{2}$-doubling experiment, the signal-to-noise ratio for the modelled SST trends is better than that for the observations.

northward flow, but is not seen in the CM2.6 simulations. This omission might be related to the model's representation of the AMOC or of wind-driven circulation in the South Atlantic, and needs further investigation.

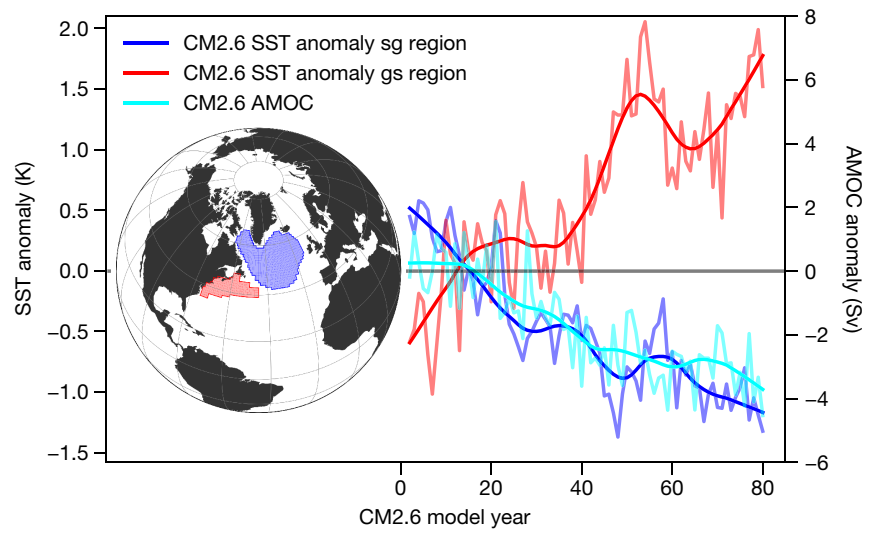

Fig. 3 | Comparison of time series of SST anomalies and the strength of the overturning circulation in the CM2.6 model. The graph shows time series of SST anomalies (relative to global mean SSTs) in the subpolar gyre (sg; dark blue) and Gulf Stream (gs; red) regions in the $\mathrm{CO}_{2}$-doubling run relative to the control run, as predicted by the CM2.6 model. These two regions are defined as shown in the inset (see Methods). The anomaly of the actual AMOC overturning rate relative to the control run is also shown (light blue). Thin lines show individual years (November to May for SSTs), and thick lines show 20-year locally weighted scatterplot smoothing (LOWESS) filtered data. Using the CMIP5 ensemble, we independently determined a conversion factor of $3.8 \mathrm{~Sv} \mathrm{~K}^{-1}$ between the SST anomaly and the AMOC anomaly.

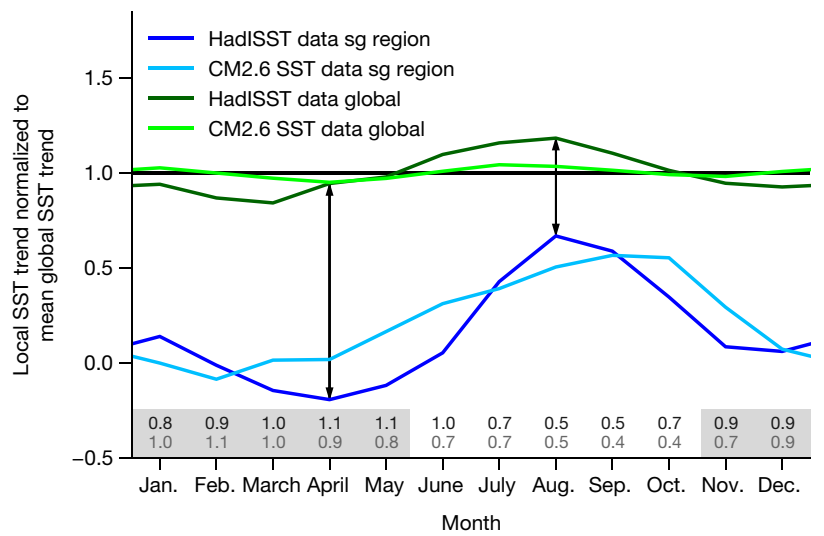

Fig. 4 Seasonal variation in SSTs in the subpolar gyre region. We show here the seasonal cycle in the normalized SST trend in the subpolar gyre (sg) region for the CM2.6 model (light blue) and HadISST data (dark blue). A value of 1 represents annual-mean, global-mean warming. In addition, we show the seasonal cycle of the normalized global-mean SST trend for the model (light green) and observations (dark green). The SST trends in the subpolar gyre region are well below the global-mean warming year-round (differences are given in numbers along the $x$ axis for the CM2.6 model (light grey) and the HadISST data (dark grey) and highlighted by arrows), yet are smallest during the cold part of the year for both observations and model. 


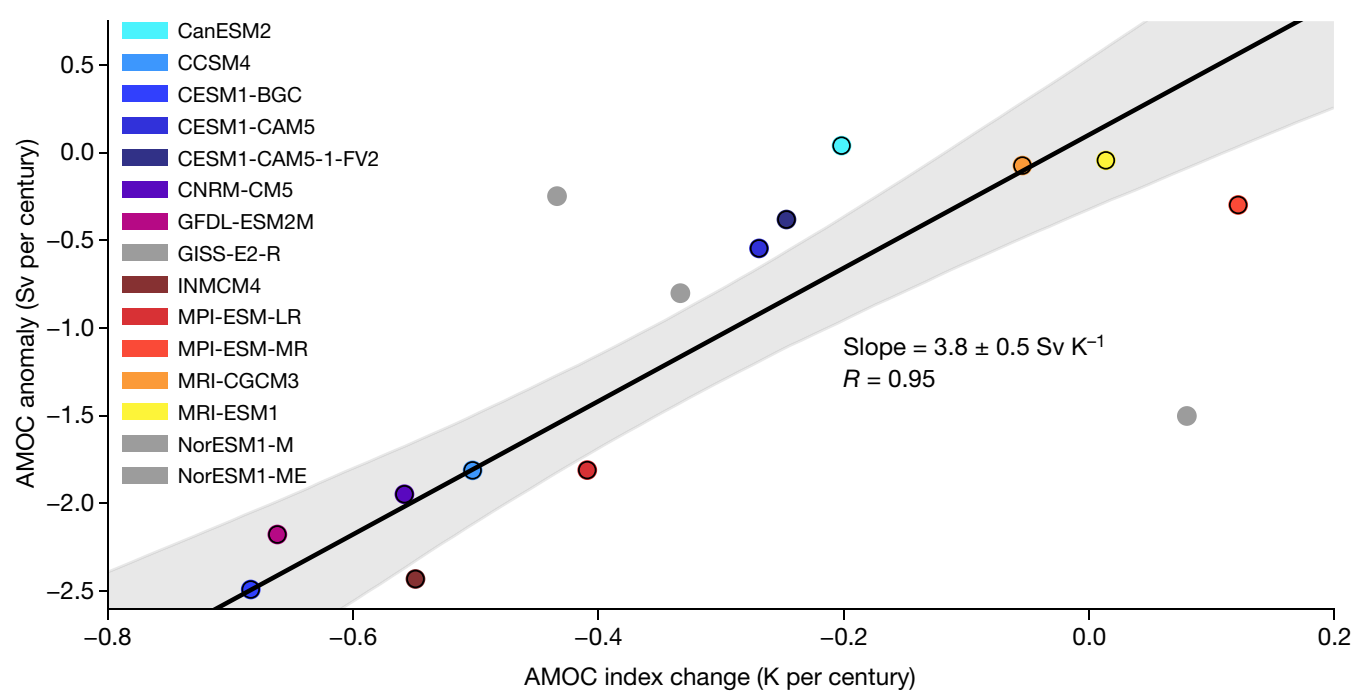

Fig. 5 Results of the CMIP5 ensemble regression analysis. The graph shows the linear trend in the simulated AMOC decline versus the SSTbased AMOC index (November-May data) in 'historic' climate model runs from 1870 to 2016, using the CMIP5 climate model ensemble. (The runs were extended from 2006 to 2016 with simulations of the RCP8.5 scenario.) Orthogonal regression analysis was performed with $n=12$ models (indicated by coloured symbols). The grey area marks the $2 \sigma$ confidence interval. The three models labelled in grey were not included in the regression owing to unrealistic AMOC representation; see Methods.

\section{The subpolar cold patch as an AMOC indicator}

The surface temperature in the subpolar gyre region, relative to the large-scale temperature trend, has been proposed as an index for longer-term AMOC variations ${ }^{7}$. Here we test and develop this concept further. Figure 4 compares the seasonal cycle in the linear SST trend in the subpolar gyre region from the HadISST data since 1870 with the 80 -year $\mathrm{CO}_{2}$-doubling experiment. The figure shows that the cooling (relative to the global mean SST) in this region is most pronounced during winter and spring. This is to be expected if the relative cold in this area is due to an AMOC slowdown and therefore driven by the ocean. In summer, a shallow surface mixed layer develops that is more susceptible to surface forcing than to horizontal heat advection, so the cold patch can be effectively capped and hidden by a warm surface layer. It typically re-emerges in autumn.

Given this result, in Fig. 2 we show the linear trends for November to May and below we propose an improved AMOC index based on these months, with a better signal-to-noise ratio than that obtained using annual data. The AMOC fingerprint pattern itself is not sensitive to the choice of the winter and spring seasons, as the linear trends of the annual data show (Extended Data Fig. 1).

\section{Performance of the AMOC index in models}

Given the hypothesis that a slowdown of the AMOC leads to a region of relative cooling near the subpolar gyre and a region of above-average warming in the vicinity of the Gulf Stream, we test whether in the models the temperatures in these regions can be used to reconstruct changes in the AMOC.

Figure 3 shows time series of the mean temperatures of the subpolar gyre (sg, dark blue line) and the Gulf Stream (gs, red line) regions relative to-that is, minus-the global mean SST. The averaging regions are defined as shown in the inset of Fig. 3 (see Methods).

The two modelled SST time series are anti-correlated $(R=-0.73)$, yet the pronounced temperature maximum in the Gulf Stream region around model year 50 (red line), which is unrelated to an AMOC change in the model (light blue line), suggests that variability due to factors other than the AMOC is substantially affecting the temperature of the warm patch. This is to be expected particularly for the coastal waters in the Gulf Stream region, which are more susceptible to wind-forced SST changes-for example, owing to the presence of strong horizontal gradients and coastal upwelling or downwelling. In accordance with this, the observed time series for the warm and cold patches are only moderately anti-correlated $(R=-0.36)$. This variability, unrelated to the AMOC, makes the warm patch unsuitable for use as an AMOC proxy owing to its poor signal-to-noise ratio, in contrast to the subpolar cold patch (see below). To maximize the signal-to-noise ratio, we base the AMOC index definition only on the subpolar gyre data (see Methods).

To test the ability of this index of detecting past AMOC changes, we turn to the CMIP5 coupled climate model ensemble ${ }^{20}$, using all simulations for which an AMOC diagnostic is available $(n=15$; Extended Data Table 1). The region defining the subpolar cold patch is chosen to be large enough to encompass the cooling found across all models, because its exact location differs in each model. Figure 5 shows the linear 1870-2016 trend in the AMOC index, as well as in the actual AMOC, in these models. The correlation for the models with a realistic AMOC has $R=0.95$, so the AMOC variation explains $89 \%$ of the

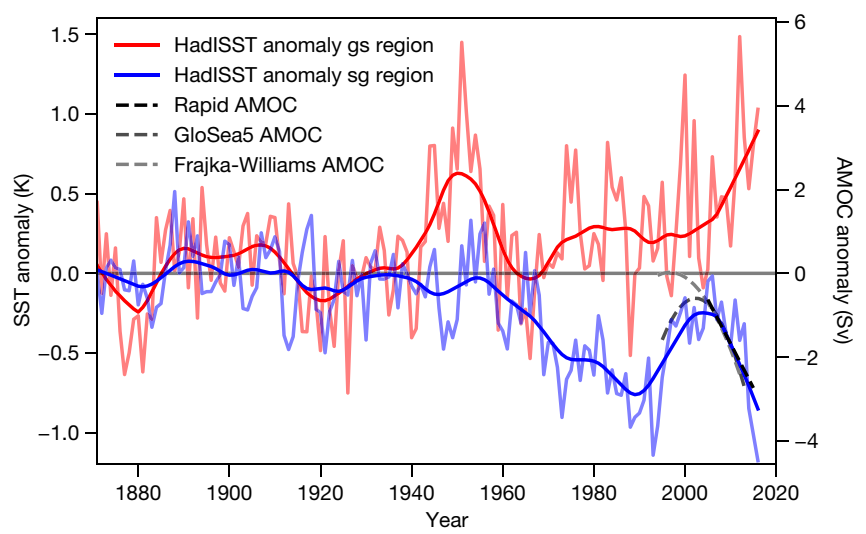

Fig. 6 | Comparison of time series of SST anomalies and the strength of the overturning circulation in observations. Shown are time series of SST anomalies with respect to the global mean SST in the subpolar gyre (sg) and the Gulf Stream (gs) regions (HadISST data). The graph also includes the trend of in situ AMOC monitoring by the RAPID project ${ }^{21}$, an ocean reanalysis product $\left(\mathrm{GloSea}^{22}\right)$ and a reconstruction from satellite altimetry and cable measurements ${ }^{23}$. Thin lines show individual years (November-May for SSTs) and thick lines show smoothed data (20-year LOWESS filtering for the SST data and quadratic/linear fits for the AMOC data). 
variance in the AMOC index. This confirms that the AMOC (at least on this long timescale) is indeed the dominant factor controlling the SST anomaly in the subpolar Atlantic. Hence the AMOC index can be used with confidence to identify the AMOC decline since 1870 . The total-least-squares line shown in Fig. 5 has a slope of $3.8 \mathrm{~Sv} \mathrm{~K}^{-1}$ and an intercept of $0.1 \mathrm{~Sv}$ for the chosen subpolar gyre region (for more information on the regression, see Methods). The very small intercept value suggests that factors other than the AMOC have a minor influence on SST changes in the subpolar Atlantic. For example, a local aerosol cooling effect, relative to the global mean SST change, would cause a systematic offset in this regression. Given that this offset is negligible, however, the slope value of $3.8 \mathrm{~Sv} \mathrm{~K}^{-1}$ can be used to calibrate between the AMOC index and the AMOC strength.

\section{AMOC time evolution}

In Fig. 6 we show the time evolution of the AMOC, reconstructed from observational SST data (blue curve)from the period 1870-2016 using the calibration factor $3.8 \mathrm{~Sv} \mathrm{~K}^{-1}$ found from the CMIP5 models (for a comparison with the earlier AMOC index ${ }^{7}$, see Extended Data Fig. 6). This time evolution suggests that the AMOC reached a minimum around 1990, recovered to a peak value in the early 2000s, and then declined again. As shown, this time evolution is consistent with the linear decline measured by the RAPID project (at $\left.26^{\circ} \mathrm{N}\right)^{21}$ since 2004, with that reconstructed by the GloSea5 ocean reanalysis ${ }^{22}$ since 1995 , and with a reconstruction from satellite altimetry and cable measurements ${ }^{23}$. It is also consistent with the finding ${ }^{24}$ of a reduction in AMOC strength of approximately $2.6 \mathrm{~Sv}$ from the end of the $1950 \mathrm{~s}$ until today, and with the observation ${ }^{25}$ of an AMOC strengthening from the 1980s until the mid-2000s. An analysis of recent (2004-2016) subsurface temperature data ${ }^{26}$ found cold subsurface anomalies around the latitude of the Gulf Stream $\left(38^{\circ} \mathrm{N}\right)$ that could be associated with a shift in the meridional position of the Gulf Stream towards the north, supporting our argument for such a shift in response to an AMOC decline.

The observed index decline of $-0.44 \mathrm{~K}$ per century translates into an AMOC trend of $-1.7 \mathrm{~Sv}$ per century, or a 2.3-Sv linear weakening over the 136-year period. As Fig. 5 shows, this AMOC decline is within the range of AMOC decline predicted by the CMIP 5 climate models in response to historic (mostly anthropogenic) forcing. Considering the 20-year smoothed curve rather than the linear trend, the AMOC weakening until today has been around $3 \mathrm{~Sv}$, and has mainly occurred since the 1950s (Fig. 6).

Comparing the SST anomalies in the CM2.6 model (Fig. 3) and observations (Fig. 6), one can see that generally they show similar magnitudes of interannual and interdecadal variability. To estimate the different types of variability, we apply a 20-year LOWESS filter ${ }^{27}$ to the data, which should largely remove any short-term variability in the SST that is unrelated to the AMOC. We estimate the interannual variability from the standard deviation of the annual time series minus the 20-year LOWESS-smoothed data. We find the variability in the cold patch to be $0.20 \mathrm{~K}$ and $0.19 \mathrm{~K}$ from the high-resolution model and observations, respectively. The interannual variability in the warm patch is $0.30 \mathrm{~K}$ for both model and observations. We estimate the interdecadal variability from the standard deviation of the 20-year LOWESS-smoothed data minus the linear trend of the smoothed data. The variability is $0.14 \mathrm{~K}$ (model) and $0.15 \mathrm{~K}$ (observations) for the cold patch, and $0.21 \mathrm{~K}$ (model) and $0.18 \mathrm{~K}$ (observations) for the warm patch. A discussion of how our results relate to the dominant modes of atmospheric variability in the North Atlantic can be found in Methods.

\section{Conclusions and impacts}

We have identified a characteristic SST fingerprint of an AMOC slowdown on the basis of high-resolution model simulations. The fingerprint consists of a cooling in the subpolar gyre region due to reduced heat transport, and a warming in the Gulf Stream region due to a northward shift of the Gulf Stream. This fingerprint is most pronounced during winter and spring, and it is found in the observed long-term temperature trends, indicating a pronounced weakening of the AMOC since the mid-twentieth century.

We have also defined an improved SST-based AMOC index, which is optimized in its regional and seasonal coverage to reconstruct AMOC changes. Analysis of an ensemble of CMIP5 model simulations confirms that this index can very well reconstruct the long-term trend of the AMOC. We calibrated the observed AMOC decline to be $3 \pm 1 \mathrm{~Sv}$ (around 15\%) since the mid-twentieth century, and reconstructed the evolution of the AMOC for the period 1870-2016. For recent decades, our reconstruction of the AMOC evolution agrees with the results of several earlier studies using different methods, suggesting that our AMOC index can also reproduce interdecadal variations.

Our findings show that in recent years the AMOC appears to have reached a new record low, consistent with the record-low annual SST in the subpolar Atlantic (since observations began in 1880) reported by the National Oceanic and Atmospheric Administration for 2015. Surface temperature proxy data for the subpolar Atlantic suggest that "the AMOC weakness after 1975 is an unprecedented event in the past millennium" 7 . This is consistent with the coral nitrogen-15 data that led Sherwood et al. ${ }^{28}$ to conclude that "the persistence of the warm, nutrient-rich regime since the early 1970s is largely unique in the context of the last approximately 1,800 yr". Although long-term natural variations cannot be ruled out entirely ${ }^{29,30}$, the AMOC decline since the 1950 s is very likely to be largely anthropogenic, given that it is a feature predicted by climate models in response to rising $\mathrm{CO}_{2}$ levels. This declining trend is superimposed by shorter-term (interdecadal) natural variability.

The AMOC weakening may already have an impact on weather in Europe. Cold weather in the subpolar Atlantic correlates with high summer temperatures over Europe, and the 2015 European heat wave has been linked to the record 'cold blob' in the Atlantic that year ${ }^{31}$. Essentially, low subpolar SSTs were found to favour an air-pressure distribution that channels warm air northwards into Europe. Model simulations further suggest that an AMOC weakening could become the "main cause of future west European summer atmospheric circulation changes" 32 , as well as potentially leading to increased storminess in Europe ${ }^{33}$. AMOC weakening has also been connected to aboveaverage sea-level rise at the US east coast ${ }^{34,35}$ and increasing drought in the Sahel ${ }^{19}$.

Continued global warming is likely to further weaken the AMOC in the long term, via changes to the hydrological cycle, sea-ice loss and accelerated melting of the Greenland Ice Sheet, causing further freshening of the northern Atlantic ${ }^{36,37}$. Given that the AMOC is one of the well documented 'tipping elements' of the climate system, with a defined threshold for collapse ${ }^{1}$, it is of considerable concern that the proximity of the Atlantic to this threshold is still poorly known $^{38-41}$.

\section{Online content}

Any Methods, including any statements of data availability and Nature Research reporting summaries, along with any additional references and Source Data files, are available in the online version of the paper at https://doi.org/10.1038/s41586018-0006-5.

Received: 20 October 2017; Accepted: 23 February 2018; Published online 11 April 2018.

1. Lenton, T. M. et al. Tipping elements in the Earth's climate system. Proc. Natl Acad. Sci. USA 105, 1786-1793 (2008).

2. Rahmstorf, S. Ocean circulation and climate during the past 120,000 years. Nature 419, 207-214 (2002)

3. Masson-Delmotte, V. et al. in Climate Change 2013: The Physical Science Basis. Contribution of Working Group I to the Fifth Assessment Report of the Intergovernmental Panel on Climate Change Ch. 5 (eds Stocker, T. F. et al.) 383-464 (Cambridge Univ. Press, Cambridge, 2013).

4. Smeed, D. A. et al. Observed decline of the Atlantic meridional overturning circulation 2004-2012. Ocean Sci. 10, 29-38 (2014).

5. Dima, M. \& Lohmann, G. Evidence for two distinct modes of large-scale ocean circulation changes over the last century. J. Clim. 23, 5-16 (2010). 
6. Drijfhout, S., van Oldenborgh, G. J. \& Cimatoribus, A. Is a decline of AMOC causing the warming hole above the North Atlantic in observed and modeled warming patterns? J. Clim. 25, 8373-8379 (2012).

7. Rahmstorf, S. et al. Exceptional twentieth-century slowdown in Atlantic Ocean overturning circulation. Nat. Clim. Chang. 5, 475-480 (2015); corrigendum 5, 956 (2015).

8. Booth, B. B. B., Dunstone, N. J., Halloran, P. R., Andrews, T. \& Bellouin, N. Aerosols implicated as a prime driver of twentieth-century North Atlantic climate variability. Nature 484, 228-232 (2012). erratum 485, 534 (2012)

9. Saba, V. S. et al. Enhanced warming of the Northwest Atlantic Ocean unde climate change. J. Geophys. Res. Oceans 121, 118-132 (2016).

10. Small, R. J. et al. A new synoptic scale resolving global climate simulation using the Community Earth System Model. J. Adv. Model. Earth Syst. 6, 1065-1094 (2014).

11. Delworth, T. L. et al. Simulated climate and climate change in the GFDL CM2.5 high-resolution coupled climate model. J. Clim. 25, 2755-2781 (2012).

12. Olson, R., An, S. I., Fan, Y., Evans, J. P. \& Caesar, L. North Atlantic observations sharpen meridional overturning projections. Clim. Dyn. https://doi. org/10.1007/s00382-017-3867-7 (2017).

13. Zhang, R. Coherent surface-subsurface fingerprint of the Atlantic meridional overturning circulation. Geophys. Res. Lett. 35, L20705 (2008).

14. Zhang, R. \& Vallis, G. K. The role of bottom vortex stretching on the path of the North Atlantic western boundary current and on the Northern Recirculation Gyre. J. Phys. Oceanogr. 37, 2053-2080 (2007).

15. Zhang, R. et al. Have aerosols caused the observed Atlantic multidecadal variability? J. Atmos. Sci. 70, 1135-1144 (2013).

16. Rayner, N. A. et al. Global analyses of sea surface temperature, sea ice, and night marine air temperature since the late nineteenth century. J. Geophys. Res. 108, D14 (2003).

17. Stocker, T.F. The seesaw effect. Science 282, 61-62 (1998)

18. Feulner, G., Rahmstorf, S., Levermann, A. \& Volkwardt, S. On the origin of the surface air temperature difference between the hemispheres in Earth's present-day climate. J. Clim. 26, 7136-7150 (2013).

19. Defrance, D. et al. Consequences of rapid ice sheet melting on the Sahelian population vulnerability. Proc. Natl Acad. Sci. USA 114, 6533-6538 (2017).

20. Taylor, K. E., Stouffer, R. J. \& Meehl, G. A. An overview of CMIP5 and the experiment design. Bull. Am. Meteorol. Soc. 93, 485-498 (2012).

21. Robson, J., Hodson, D., Hawkins, E. \& Sutton, R. Atlantic overturning in decline? Nat. Geosci. 7, 2-3 (2014).

22. Jackson, L. C., Peterson, K. A., Roberts, C. D. \& Wood, R. A. Recent slowing of Atlantic overturning circulation as a recovery from earlier strengthening. Nat. Geosci. 9, 518-522 (2016).

23. Frajka-Williams, E. Estimating the Atlantic overturning at $26^{\circ} \mathrm{N}$ using satellite altimetry and cable measurements. Geophys. Res. Lett. 42, 3458-3464 (2015).

24. Kanzow, T. et al. Seasonal variability of the Atlantic Meridional Overturning Circulation at $26.5^{\circ}$ N. J. Clim. 23, 5678-5698 (2010).

25. Latif, M. et al. Is the thermohaline circulation changing? J. Clim. 19, 4631-4637 (2006)

26. Frajka-Williams, E., Beaulieu, C. \& Duchez, A. Emerging negative Atlantic multidecadal oscillation index in spite of warm subtropics. Sci. Rep. 7, 11224 (2017).

27. Cleveland, W. S. Robust locally weighted regression and smoothing scatterplots. J. Am. Stat. Assoc. 74, 829-836 (1979).

28. Sherwood, O. A., Lehmann, M. F., Schubert, C. J., Scott, D. B. \& McCarthy, M. D. Nutrient regime shift in the western North Atlantic indicated by compoundspecific delta15N of deep-sea gorgonian corals. Proc. Natl Acad. Sci. USA 108 1011-1015 (2011)

29. Bakker, P., Clark, P. U., Golledge, N. R., Schmittner, A. \& Weber, M. E. Centennialscale Holocene climate variations amplified by Antarctic Ice Sheet discharge. Nature 541, 72-76 (2017).

30. Laepple, T. \& Huybers, P. Ocean surface temperature variability: large model-data differences at decadal and longer periods. Proc. Natl Acad. Sci. USA 111, 16682-16687 (2014).

31. Duchez, A. et al. Drivers of exceptionally cold North Atlantic Ocean temperatures and their link to the 2015 European heat wave. Environ. Res. Lett 11, 074004 (2016).
32. Haarsma, R. J., Selten, F. M. \& Driifhout, S. S. Decelerating Atlantic meridional overturning circulation main cause of future west European summer atmospheric circulation changes. Environ. Res. Lett. 10, 094007 (2015).

33. Jackson, L. C. et al. Global and European climate impacts of a slowdown of the AMOC in a high resolution GCM. Clim. Dyn. 45, 3299-3316 (2015).

34. Sallenger, A. H., Doran, K. S. \& Howd, P. A. Hotspot of accelerated sea-level rise on the Atlantic coast of North America. Nat. Clim. Change 2, 884-888 (2012).

35. Ezer, T. Detecting changes in the transport of the Gulf Stream and the Atlantic overturning circulation from coastal sea level data: the extreme decline in 2009-2010 and estimated variations for 1935-2012. Global Planet. Change 129, 23-36 (2015).

36. Bakker, P. et al. Fate of the Atlantic Meridional Overturning Circulation: strong decline under continued warming and Greenland melting. Geophys. Res. Lett 43, 12252-12260 (2016).

37. Böning, C. W., Behrens, E., Biastoch, A., Getzlaff, K. \& Bamber, J. L. Emerging impact of Greenland meltwater on deepwater formation in the North Atlantic Ocean. Nat. Geosci. 9, 523-527 (2016).

38. Liu, W., Liu, Z. \& Brady, E. C. Why is the AMOC monostable in coupled general circulation models? J. Clim. 27, 2427-2443 (2014).

39. Liu, W., Xie, S.-P., Liu, Z. \& Zhu, J. Overlooked possibility of a collapsed Atlantic Meridional Overturning Circulation in warming climate. Sci. Adv. 3, e1601666 (2017).

40. Hofmann, M. \& Rahmstorf, S. On the stability of the Atlantic meridional overturning circulation. Proc. Natl Acad. Sci. USA 106, 20584-20589 (2009).

41. Buckley, M. W. \& Marshall, J. Observations, inferences, and mechanisms of the Atlantic Meridional Overturning Circulation: a review. Rev. Geophys. 54, 5-63 (2016).

Acknowledgements We acknowledge the World Climate Research Programme's Working Group on Coupled Modelling, which is responsible for CMIP, and we thank the climate modelling groups listed in Extended Data Table 1 for producing and making available their model output. For CMIP, the US Department of Energy's Program for Climate Model Diagnosis and Intercomparison provides coordinating support and led the development of software infrastructure in partnership with the Global Organization for Earth System Science Portals. Data from the RAPID-WATCH meridional overturning circulation monitoring project were generated with funding from the Natural Environment Research Council and are freely available from www.rapid. ac.uk/rapidmoc. We thank L. Jackson for the GloSea5 reanalysis data, and E. Frajka-Williams for the AMOC reconstruction from satellite altimetry and cable measurements. We also thank the personel of National Oceanic and Atmospheric Administration's GFDL for investeing time and resources into the development of CM2.6, which was evaluated in this research. A.R. was funded by the Marie Curie Horizon2020 project CONCLIMA (grant number 703251). PIK is a Member of the Leibniz Association.

Reviewer information Nature thanks S. Gulev, A. Schmittner and the other anonymous reviewer(s) for their contribution to the peer review of this work.

Author contributions L.C. performed the research and wrote the manuscript together with S.R. S.R. designed the study. A.R. performed the CMIP5 analyses. G.F. helped to interpret the results. V.S. provided the CM2.6 analysis and simulations. All authors discussed the results and provided input to the manuscript.

Competing interests The authors declare no competing interests.

Additional information

Extended data are available for this paper at https://doi.org/10.1038/s41586018-0006-5.

Reprints and permissions information is available at http://www.nature.com/ reprints.

Correspondence and requests for materials should be addressed to L.C. or S.R. Publisher's note: Springer Nature remains neutral with regard to jurisdictional claims in published maps and institutional affiliations. 


\section{METHODS}

Climate model simulations. The CM2.6 coupled global climate model was developed by the Geophysical Fluid Dynamics Laboratory of the National Oceanic and Atmospheric Administration. It includes an atmospheric general circulation model at an average horizontal resolution of $0.5 \times 0.5$ degrees $(50 \mathrm{~km})$ and an ocean circulation model at $0.1 \times 0.1$ degrees $(10 \mathrm{~km})^{9,11,42}$. The ocean has 50 vertical levels and includes a sea-ice model. Two simulations were performed that were both initialized from present-day ocean conditions, followed by a spin-up time of 100 years at constant $1860 \mathrm{CO}_{2}$ levels. The control simulation, of 80 years' duration, then maintained $\mathrm{CO}_{2}$ concentrations at the 1860 level; in the experimental run, by contrast, atmospheric $\mathrm{CO}_{2}$ increased by $1 \%$ per year over 70 years until it doubled, and then remained at this level for another 10 years. Given the extremely high computational cost of this model (approximately one day per one year of simulation on a high-performance computer), no further simulations are available.

Definition of the AMOC index. We define the AMOC index $I_{\mathrm{AMOC}}$ as the difference between the mean SST of the geographic region that is most sensitive to a reduction in the AMOC (the subpolar gyre region, sg) and that of the whole globe:

$$
I_{\mathrm{AMOC}}=\overline{\mathrm{SST}_{\mathrm{sg}}}-\overline{\mathrm{SST}_{\text {global }}}
$$

Rather than including the whole year, we instead use only the winter and spring months (November to May), because the AMOC signal found in the SST is most pronounced during these seasons (see Fig. 4). Thus the AMOC index for a certain year is defined as the mean SST in the subpolar gyre region for the following November-May season, minus the global mean SST for that season.

Definition of the subpolar gyre region. To define the region used to calculate the AMOC index (shown in the inset of Fig. 3), we assumed that SST differences in the subpolar North Atlantic relative to the global mean SST are dominated by variations in the AMOC. For this study, we determined this region by combining normalized linear SST trends from both the HadISST dataset and the highresolution CM2.6 model run, as shown in Fig. 2. Grid cells that show relative cooling in either the observations or the model were included in the definition. The region is large (compared, for example, with that used in ref. ${ }^{7}$ ), which has the advantage that it should cover most of the area in which the heat transported northwards by the AMOC is vented to the atmosphere in the observations and in the models, especially considering that the exact location of heat release is, to some degree, model-dependent. The exact coordinates of the region are available in a public data repository (see Data availability).

Definition of the Gulf Stream region. Similar to the subpolar gyre region, the Gulf Stream region is defined as the region that covers the above-average longterm warming east of the US coast that results from an AMOC slowdown in both observations and model (see inset of Fig. 3). Thus, the terms Gulf Stream region and subpolar gyre region do not refer directly to ocean circulation features, but rather to SST features. The exact coordinates of the region are available in a public data repository (see Data availability).

AMOC effects on Gulf Stream separation point and DWBC strength. We link the extreme warming observed along the US coast to the Gulf Stream shifting northwards and closer to shore as a consequence of an AMOC slowdown. For the MOM4 ocean model, it has been shown that the correct separation point of the Gulf Stream is achieved through a reasonable representation of the $\mathrm{DWBC}^{14}$. Furthermore it has been shown that, for this model, a weakening of the AMOC is accompanied by a weakening of the DWBC and that both are followed by a northward shift of the mean Gulf Stream path ${ }^{43,44}$. The combination of these results indicates that, in the model run, the observed warming is indeed due to a weakened AMOC that leads to a weakened DWBC, a weakened northern recirculation gyre and a northern shift of the Gulf Stream separation point. To test this, we compared the evolution of the Gulf Stream path (represented by the Gulf Stream index-that is, the mean latitude of the $15^{\circ} \mathrm{C}$ isotherm at a 200 -m depth in the Northwest Atlantic, between $75^{\circ} \mathrm{W}$ and $55^{\circ} \mathrm{W}^{44}$ ) with the AMOC strength at $26^{\circ} \mathrm{N}$ in the $\mathrm{CM} 2.6$ control run and the $\mathrm{CO}_{2}$-doubling run (Extended Data Fig. 4a).

We compared the AMOC strength to the summed southward deep-ocean transport (between depths of $1,000 \mathrm{~m}$ and $4,000 \mathrm{~m}$ ) at $40^{\circ} \mathrm{N}$ in the region between the coast and $65^{\circ} \mathrm{W}$, for the $\mathrm{CM} 2.6$ control run and the $\mathrm{CO}_{2}$-doubling run (Extended Data Fig. 4b). We found that the DWBC in the model indeed weakens as the AMOC slows down, and by a very similar amount (around $3.5 \mathrm{~Sv}$ ). We calculated the DWBC at this latitude because it is just north of the region where the Gulf Steam and DBWC cross in the control run, and is thus the area where the northern recirculation gyre forms, which forces the Gulf Stream to deflect from the coast. These analyses confirm that the AMOC weakening in the model is indeed accompanied by a weakened DWBC and a northerly shift of the Gulf Stream path. Analysis of additional observational datasets. For this study, we analysed seven available SST data products. All of them show the fingerprint of the AMOC, namely, the cold patch in the subpolar Atlantic and, to a greater or lesser extent, the enhanced warming inshore of the Gulf Stream (Extended Data Fig. 5). Details of the different datasets are given in Extended Data Table 1. Different choices of processing steps lead to distinctions in the representation of spatial and temporal variability in the datasets. We focused on the dataset with the best spatial resolution and advanced quality control, the HadISST data. Although the ERSST data are also quality-controlled, the use of empirical orthogonal teleconnections for postprocessing leads to a smoothing of the SST signal in the spatial domain (unwanted for this study). The bias adjustments and quality-control procedures used for the likewise high-resolution COBE dataset are not as advanced as those used for the HadISST and ERSST data. The SODA data are an ocean reanalysis product, that is, they are based on model simulations with data assimilation.

Significance of the 1870-2016 trends. To illustrate the significance of the 18702016 linear trends, we compare the distribution of the long-term trends for all grid cells between $60^{\circ} \mathrm{S}$ and $75^{\circ} \mathrm{N}$ with the distribution of trends for the grid cells in the subpolar gyre region and with the grid cells in the Gulf Stream region (defined in the inset of Fig. 3). (We exclude the sea-ice-covered regions because they are expected to show no temperature trend, consistent with the assumption that SSTs remain close to freezing point there.) Extended Data Fig. 3 shows the global distributions of relative SST trends for the HadISST data and the $\mathrm{CO}_{2}$-doubling run of the CM2.6 model. Assuming a constant bin size of 0.2 , we determined the $5 \%$ and $95 \%$ quantiles. The medians of the subpolar gyre and Gulf Stream regions lay in all cases within the lowest and highest $5 \%$ of the trends. The median of the Gulf Stream region in the HadISST data is 2.4 (that is, the warming here is 2.4 times larger than the global SST warming), higher than $96 \%$ of the SST trends; the median of the subpolar gyre region is -0.17 , and thus among the lowest $3 \%$ of the trends. In the $\mathrm{CO}_{2}$-doubling run of the $\mathrm{CM} 2.6$ model, the AMOC fingerprint regions are even greater outliers, presumably because the larger global-warming signal and associated greater AMOC weakening result in a better signal-to-noise ratio. The median of the Gulf Stream region in the models is 2.4, higher than 98\% of the SST trends, and the median of the subpolar gyre region is -0.25 , among the lowest $1 \%$ of the trends.

Relation between the AMOC index and the overturning strength. To assess and calibrate the relation between changes in the AMOC index and the AMOC strength, we examined the AMOC index and AMOC simulations performed using 15 models in the context of CMIP5 for the historical (1870-2005) climate, extended to 2016 using simulations of the RCP8.5 scenario. To assess whether the models have a reasonable representation of the AMOC, we compared the mean maximum AMOC at $26^{\circ} \mathrm{N}$ for the model years 2005-2014 with the mean of the observed AMOC at around $26^{\circ} \mathrm{N}$ during that period (16.8 Sv; see Extended Data Table 1). We chose models with mean maximum AMOCs of $16.8 \pm 10.0 \mathrm{~Sv}$; this excluded the NorESM1-M and Nor-ESM1-ME models. We further excluded the GISS-E2-R model because it is an outlier with a very unrealistic deep mixed layer that reaches down to the sea floor in most of the subpolar Atlantic ${ }^{45}$.

Total-least-squares fit. To test the relation between our AMOC index and the AMOC strength, we performed a total-least-squares fit (also known as an orthogonal regression, because the error in both variables is minimized - that is, the error is orthogonal to the regression line). The full regression equation is:

$$
Y=3.8 \mathrm{~Sv} \mathrm{~K}^{-1} \times X+0.1 \mathrm{~Sv} \text { per century }
$$

where $X$ is the trend in AMOC indices, in kelvins per century, and $Y$ is the corresponding trend in AMOC strength, in sverdrups per century.

Sensitivity to extension of the subpolar gyre region. The region chosen as the subpolar gyre region is, on average, largely free of sea ice (to analyse this, we compared the region with the average November-May sea-ice cover from the HadISST data). To explore how partly ice-covered areas influence the index, we limited the region to ice-free areas (determined by the maximum sea-ice cover for the November-May season from 1870 to 2016), and compared the resulting index with our original AMOC index (Extended Data Fig. 7). This shows some differences in the year-to-year variations, but the longer-term trend, especially in the last decades, is hardly affected at all. Thus we conclude that sea ice does not affect our AMOC index.

Comparison with a previous AMOC index. Rahmstorf et al. ${ }^{7}$ used a different region and different data (annual HadCRUT4 SSTs minus their annual Northern Hemispheric mean, both land and ocean) to obtain the AMOC index. We calculate the AMOC index relative to the global mean SST; however, as our comparison of the two indices shows, the index is not sensitive to this choice (Extended Data Fig. 6). Rahmstorf et al. ${ }^{7}$ also determined the conversion factor between their AMOC index and the actual AMOC by using only one model, MPI-ES-MR. We updated their AMOC index with the latest data and compared it with the AMOC slowdown determined herein (Extended Data Fig. 6). The results that we obtained with both index definitions are highly consistent on the multidecadal timescale of interest. 
Link to empirical modes of variability. Two main modes of variability have been defined in the North Atlantic, primarily on the basis of empirical data: the North Atlantic Oscillation (NAO) and the Atlantic Multidecadal Oscillation (AMO). The former describes atmospheric variability, with an index based on the surface pressure gradient ${ }^{46}$, whereas the latter describes SST variability relative to the global mean-similar to our AMOC index, but including Atlantic SSTs down to the Equator. Both NAO and AMO indices show a correlation with our AMOC index (Extended Data Figs. 8, 9).

For the AMO index this is not surprising, given that it has the subpolar SST data in common with our AMOC index. However, the usefulness of the AMO index is limited by the fact that it conflates subpolar SST variability and tropical SST variability into one index ${ }^{47}$. For our purpose of using SSTs to deduce AMOC variations, this degrades the signal-to-noise ratio. Furthermore, it can be seen that the decadal variations in our AMOC index are similar to those of the AMO index (Extended Data Fig. 8b), which is in accordance with other studies showing that the time evolution of the AMO can at least partly be explained by changes in Atlantic Ocean currents ${ }^{48,49}$. Yet because the AMO conflates two regions with different long-term trends-that is, the subpolar North Atlantic, which is cooling, and the tropics and subtropics, which are warmer with temperature trends at or above the rate of the global mean (Fig. 2)-it does not show the 1870-2016 negative trend that is clearly visible in our AMOC index (Extended Data Fig. 8a).

The NAO index is more useful, as it can be used to study the relationship between atmospheric-pressure variability and North Atlantic SSTs. We find a clear negative correlation with $R=-0.54$ between the decadally smoothed time series of the AMOC and the NAO indices, which occurs when the AMOC leads the NAO by three years (see Extended Data Fig. 9b). This negative correlation, and the fact that a pronounced cooling in the subpolar North Atlantic has been shown to be followed by a positive phase of the $\mathrm{NAO}^{50}$, suggests that on interdecadal timescales the AMOC at least partially drives NAO changes via changes in North Atlantic SSTs, rather than the other way round. Consistent with this, the NAO index shows a positive trend for 1870-2016 (Extended Data Fig. 9a). A positive $\mathrm{NAO}$, on the other hand, helps to extract heat from the subpolar ocean through enhanced westerly winds over that region, cooling SSTs, enhancing convection and increasing ocean density ${ }^{51}$. This acts as a negative feedback on an AMOC weakening. Such a delayed negative feedback could either dampen the AMOC response or lead to oscillatory behaviour. Further investigation of this linkage is beyond the scope of this study. Nevertheless, our work supports the importance of ocean circulation to variations in the North Atlantic SST pattern, which has been highlighted previously ${ }^{52,53}$.

Code availability. Code for running the CM2.6 experiment is available from http:// www.gfdl.noaa.gov/. Scripts for analysing the data are available from the corresponding authors upon reasonable request.

Data availability. The SST datasets analysed here are publicly available; detailed information is given in Extended Data Table 1. The CMIP5 model output is available from https://esgf-node.llnl.gov/projects/cmip5/. The CM2.6 model output is available from V.S. (vincent.saba@noaa.gov) upon reasonable request. The exact definitions of the subpolar gyre and Gulf Stream region, as well as the SST anomalies of these regions, are available in a public data repository: http:// www.pik-potsdam.de/ caesar/AMOC_slowdown/. The data for the GloSea reanalysis were provided by L. Jackson ${ }^{22}$. The data for the reconstruction from satellite altimetry and cable measurements were provided by E. Frajka-Williams ${ }^{23}$.
RAPID data are available from http://www.rapid.ac.uk/rapidmoc/rapid_data/ datadl.php.

42. Griffies, S. M. et al. Impacts on ocean heat from transient mesoscale eddies in a hierarchy of climate models. J. Clim. 28, 952-977 (2015).

43. Zhang, R. \& Vallis, G. K. Impact of great salinity anomalies on the low-frequency variability of the North Atlantic climate. J. Clim. 19, 470-482 (2006).

44. Sanchez-Franks, A. \& Zhang, R. Impact of the Atlantic meridional overturning circulation on the decadal variability of the Gulf Stream path and regional chlorophyll and nutrient concentrations. Geophys. Res. Lett. 42, 9889-9897 (2015).

45. Heuzé, C. North Atlantic deep water formation and AMOC in CMIP5 models. Ocean Sci. 13, 609-622 (2017).

46. Visbeck, M. H., Hurrell, J. W., Polvani, L. \& Cullen, H. M. The North Atlantic Oscillation: past, present, and future. Proc. Natl Acad. Sci. USA 98, 1287612877 (2001).

47. Frankignoul, C., Gastineau, G. \& Kwon, Y.-O. Estimation of the SST response to anthropogenic and external forcing and its impact on the Atlantic Multidecadal Oscillation and the Pacific Decadal Oscillation. J. Clim. 30, 9871-9895 (2017).

48. Zhang, R., Delworth, T. L. \& Held, I. M. Can the Atlantic Ocean drive the observed multidecadal variability in Northern Hemisphere mean temperature? Geophys. Res. Lett. 34, L02709 (2007)

49. O'Reilly, C. H., Huber, M., Woollings, T. \& Zanna, L. The signature of lowfrequency oceanic forcing in the Atlantic Multidecadal Oscillation. Geophys. Res. Lett. 43, 2810-2818 (2016).

50. Gastineau, G. \& Frankignoul, C. Influence of the North Atlantic SST variability on the atmospheric circulation during the twentieth century. J. Clim. 28, 1396-1416 (2015).

51. Delworth, T. L. \& Zeng, F. The impact of the North Atlantic Oscillation on climate through its influence on the Atlantic Meridional Overturning Circulation. J. Clim. 29, 941-962 (2016).

52. Delworth, T. L. et al. The central role of ocean dynamics in connecting the North Atlantic Oscillation to the extratropical component of the Atlantic Multidecadal Oscillation. J. Clim. 30, 3789-3805 (2017).

53. Zhang, R. On the persistence and coherence of subpolar sea surface temperature and salinity anomalies associated with the Atlantic multidecadal variability. Geophys. Res. Lett. 44, 7865-7875 (2017).

54. Huang, B. et al. Extended reconstructed sea surface temperature, version 5 (ERSSTv5): upgrades, validations, and intercomparisons. J. Clim. 30, 8179-8205 (2017).

55. Huang, B. et al. Extended reconstructed sea surface temperature version 4 (ERSST.v4). Part I: upgrades and Intercomparisons. J. Clim. 28, 911-930 (2015).

56. Smith, T. M., Reynolds, R. W., Peterson, T. C. \& Lawrimore, J. Improvements to NOAA's historical merged land-ocean surface temperature analysis (1880-2006). J. Clim. 21, 2283-2296 (2008).

57. Kaplan, A., Cane, M. A., Kushnir, Y., Clement, A. C., Blumenthal, M. B. \& Rajagopalan, R. Analyses of global sea surface temperature 1856-1991. J. Geophys. Res. Oceans 103, 18567-18589 (1998).

58. Carton, J. A. \& Giese, B. S. A reanalysis of ocean climate using Simple Ocean Data Assimilation (SODA). Mon. Weath. Rev 136, 2999-3017 (2008).

59. Hirahara, S., Ishii, M. \& Fukuda, Y. Centennial-scale sea surface temperature analysis and its uncertainty. J. Clim. 27, 57-75 (2014).

60. Trenberth, K. E. \& Shea, D. J. Atlantic hurricanes and natural variability in 2005. Geophys. Res. Lett. 33, L12704 (2006).

61. Hurrell, J. W. Decadal trends in the North Atlantic Oscillation: regional temperatures and precipitation. Science 269, 676-679 (1995).

62. Intergovermental Panel on Climate Change. Climate Change 2013: The Physical Science Basis. Contribution of Working Group I to the Fifth Assessment Report of the Intergovernmental Panel on Climate Change (Cambridge University Press, Cambridge, 2013). 

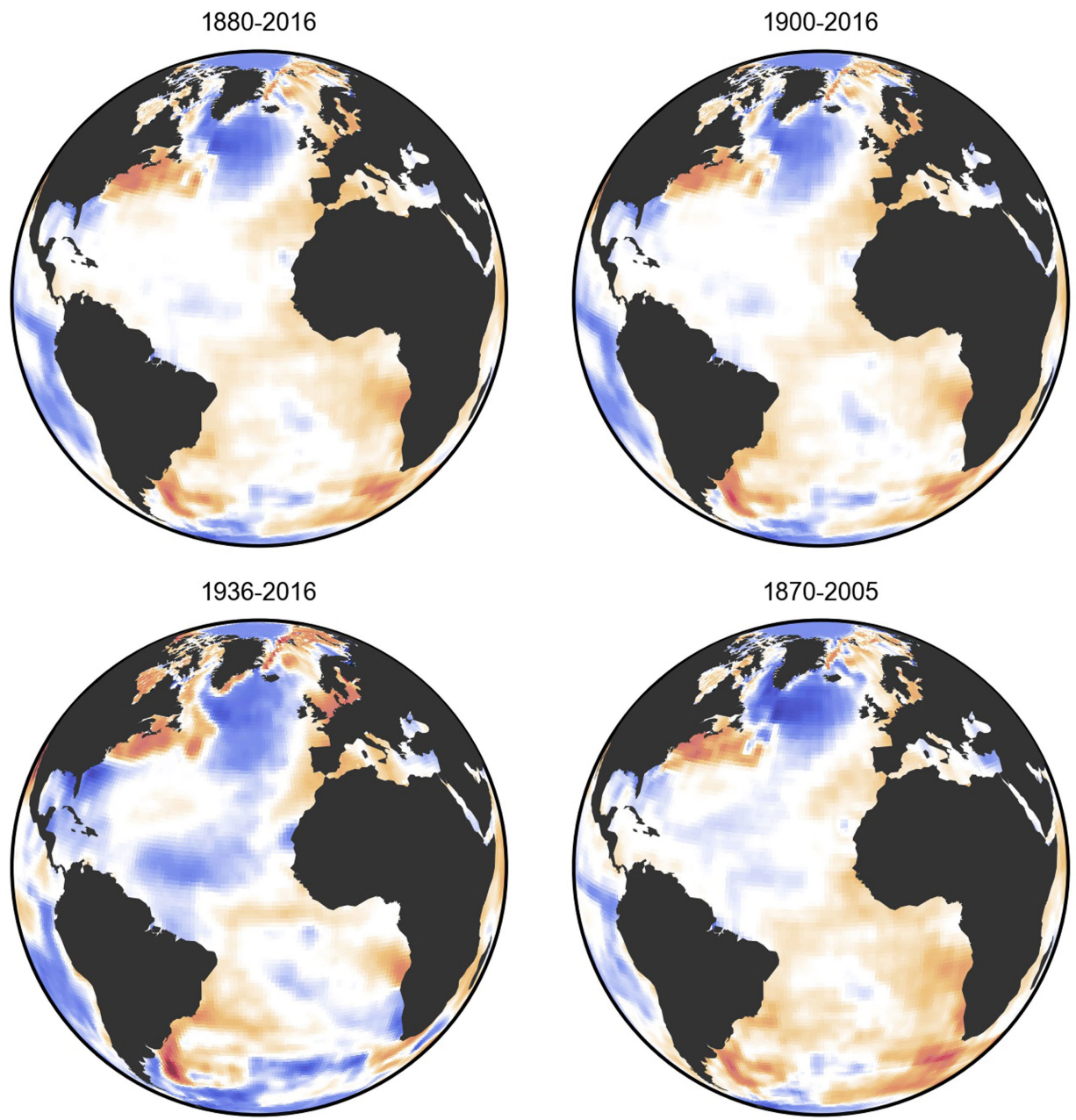

1870-1995

1880-1985
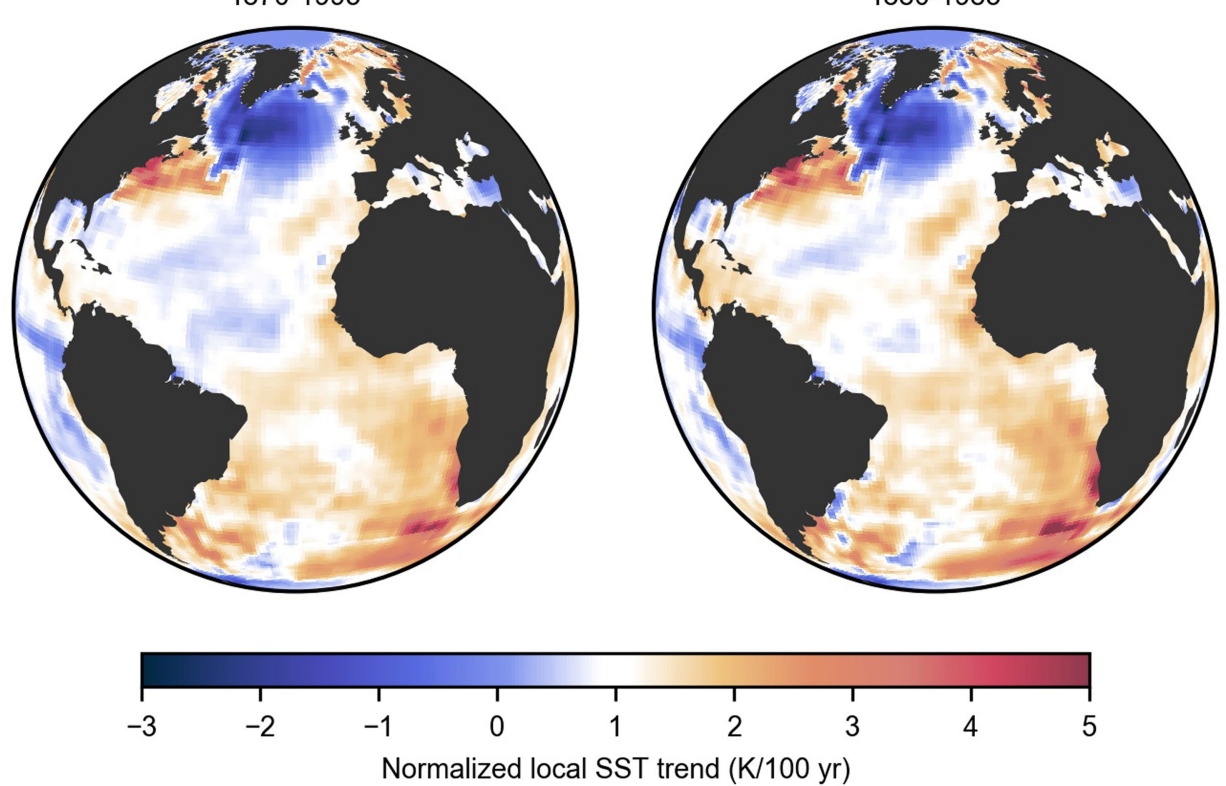

Extended Data Fig. 1 | Normalized SST trends in the HadISST data for different time periods. Observed linear SST trends (using annual HadISST data), calculated for different timespans to test the robustness of the linear SST trend pattern to the starting and ending years of the timespan. The pattern is normalized with the respective global mean SST trend. Regions that show below-average warming or cooling are in blue; regions that show above-average warming are in red. 

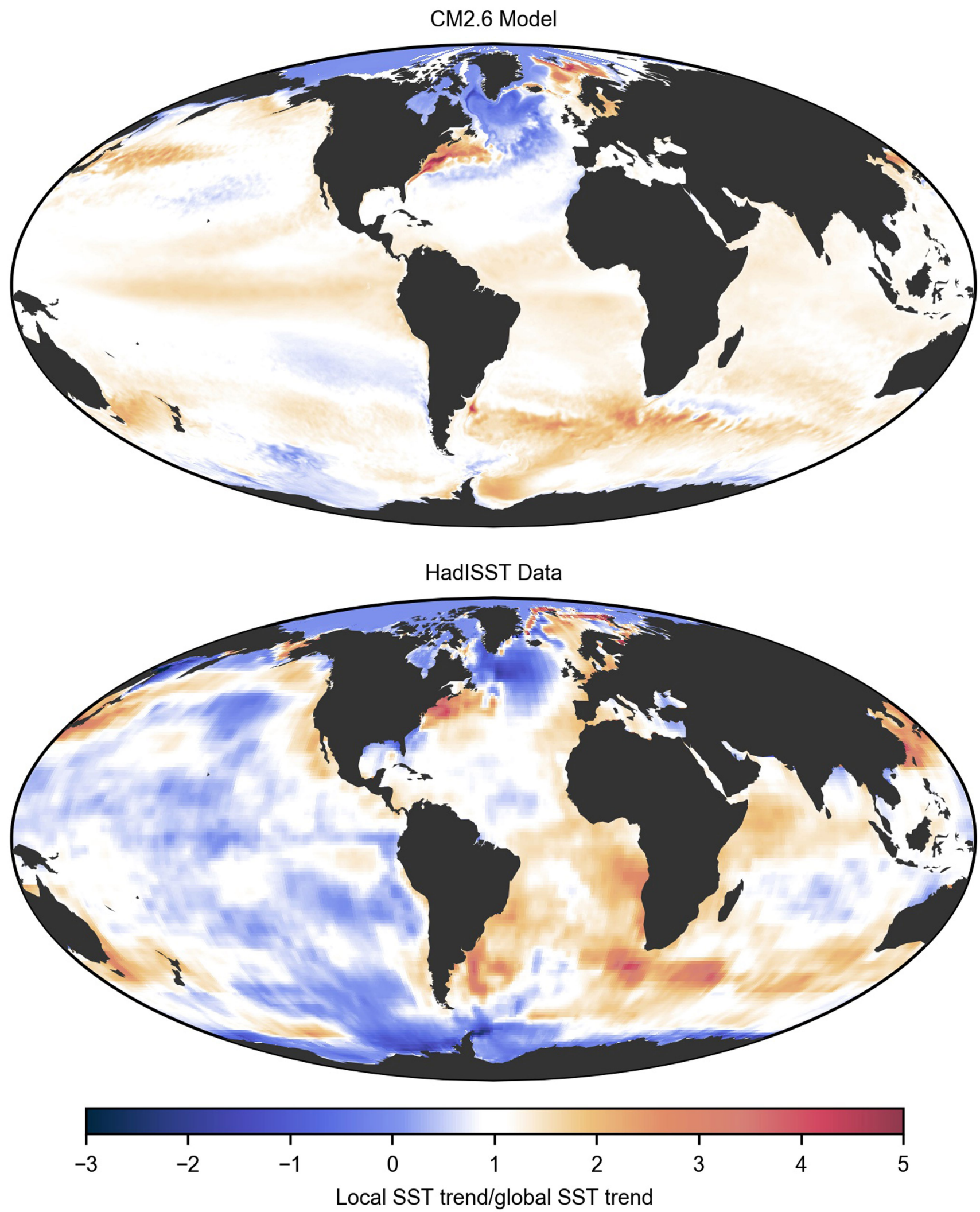

Extended Data Fig. 2 | Comparison of global normalized SST trends. Linear SST trends during a $\mathrm{CO}_{2}$-doubling experiment using the GFDL CM2.6 climate model (top), and observed trends during 1870-2016

(HadISST data, bottom), both normalized with the respective global mean SST trends and using data from the November-May season. Regions that show cooling or below-average warming are in blue; regions that show above-average warming are in red. Note again that owing to the much greater climate change in the $\mathrm{CO}_{2}$-doubling experiment, the signalto-noise ratio for the modelled SST trends is better than that for the observations, and thus the noise level is suppressed by the normalization. 


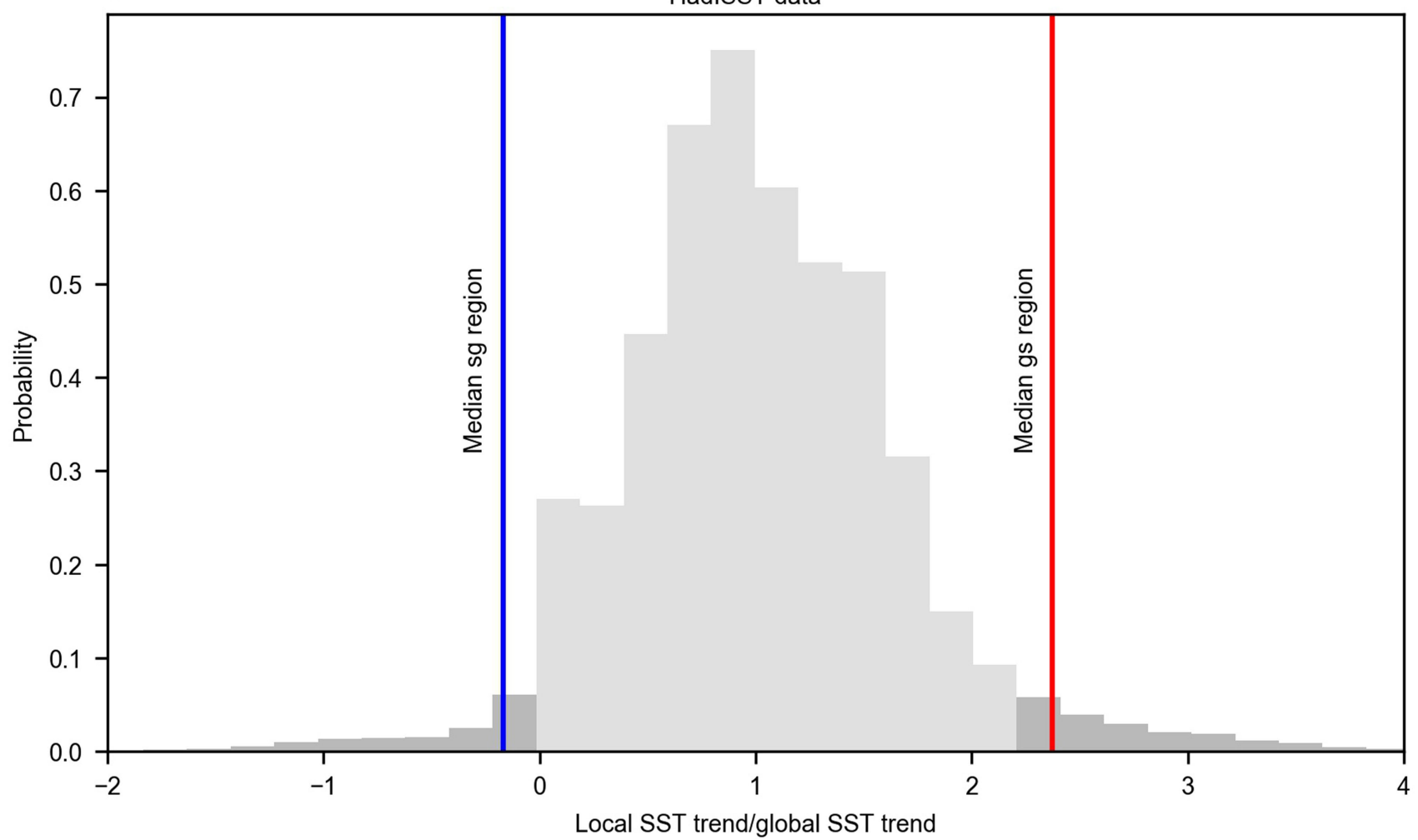

b

CM2.6 data

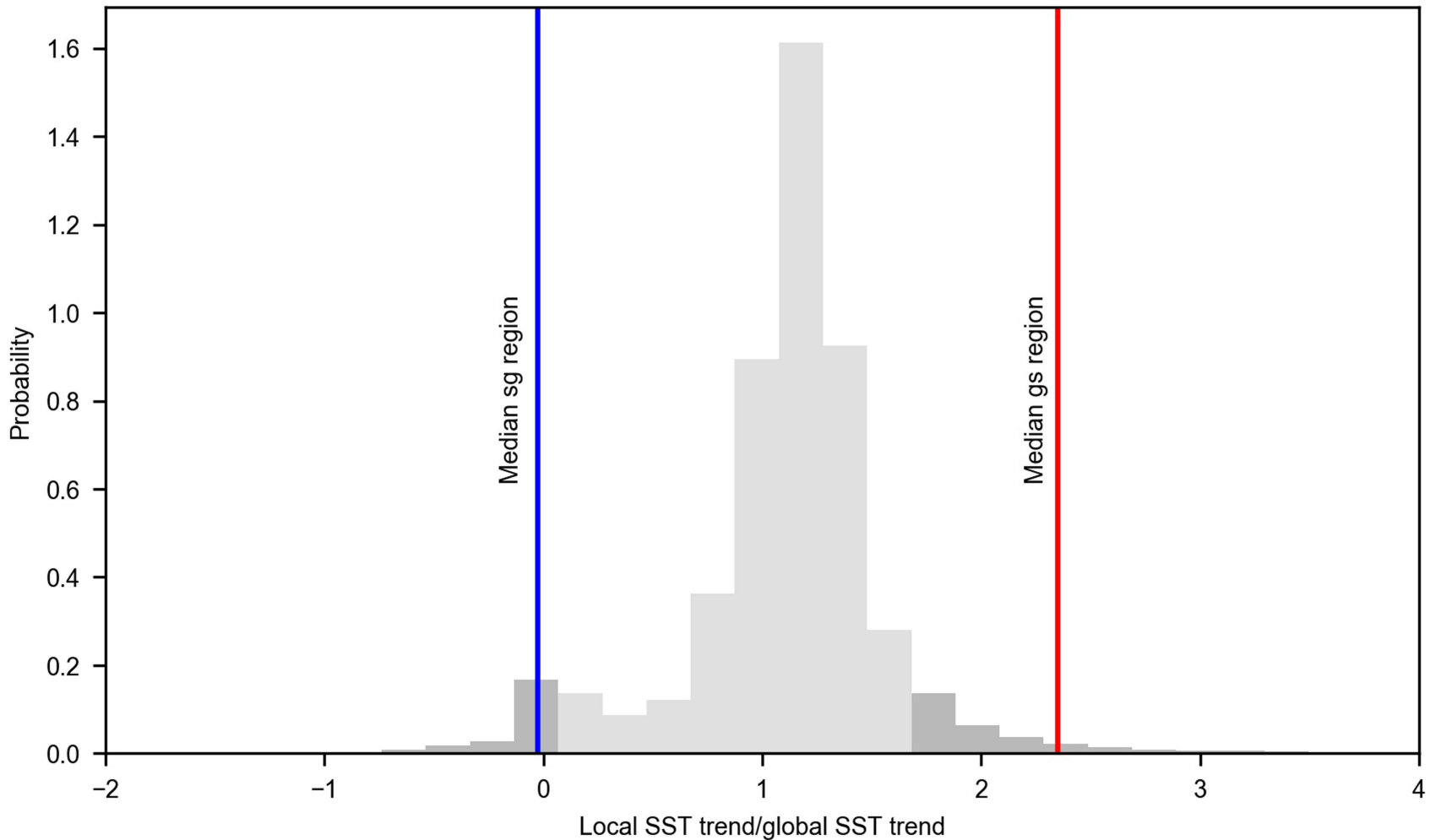

Extended Data Fig. 3 | Histograms showing the distribution of the normalized longer-term trends. a, The distribution (grey bars) of all local trends, normalized to the global trends, from the HadISST data for 18702016 , for latitudes between $60^{\circ} \mathrm{S}$ and $75^{\circ} \mathrm{N}$. The distribution is located around $\mu=1$ with a standard deviation of $\sigma=0.66$ (grey bars). The 5th and 95th percentiles are marked in darker grey. The distribution of the 18702016 trends for grid cells assigned to the subpolar gyre regions is shifted to lower or even negative values, with a median of $\widetilde{x}_{\mathrm{sg}}=-0.17$ (blue). The distribution of trends for grid cells in the Gulf Stream region are shifted to higher values, with a median of $\widetilde{x}_{\mathrm{gs}}=2.4$ (red). The distributions are normalized to account for the different sample sizes of global, subpolar gyre and Gulf Stream regions. b, As for panel a, but for the $\mathrm{CO}_{2}$-doubling run of the CM2.6 model, with $\mu=1.1, \sigma=0.48, \widetilde{x}_{\mathrm{sg}}=-0.02$ and $\widetilde{x}_{\mathrm{gs}}=2.4$. The standard deviations of the model data are expected to be smaller than those of the observations because of the larger climate-change signal by which the model data are normalized; this reduces the 'noise' of short-term variability relative to the climate signal. 

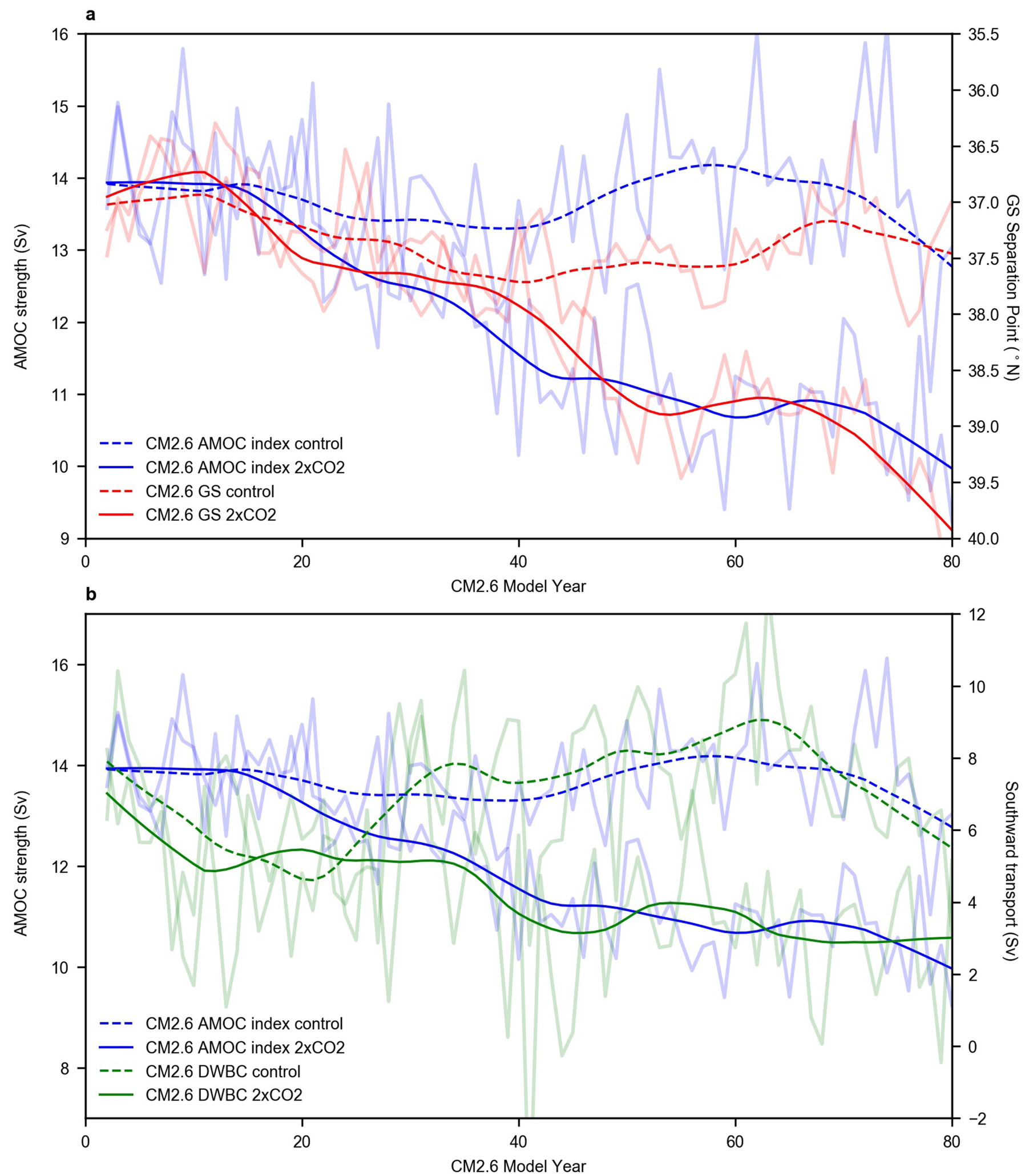

Extended Data Fig. 4 | Influence of the AMOC on the separation point of the Gulf Stream. a, The evolution of the Gulf Stream (GS) separation point compared with the AMOC strength in the $\mathrm{CM} 2.6$ control and $\mathrm{CO}_{2}$ doubling runs, as indicated by the Gulf Stream index ${ }^{44}$. The graph shows a link between a weaker AMOC and a northward shift of the separation point. $\mathbf{b}$, Time series of the southward transport of the deep ocean current (summed between depths of $1,000 \mathrm{~m}$ and $4,000 \mathrm{~m}$ ) at $40^{\circ} \mathrm{N}$ in the region between the US coast and $65^{\circ} \mathrm{W}$ (see Methods), showing a weakening DWBC during the $\mathrm{CO}_{2}$-doubling experiment. The thin lines show annual values, the thick lines show the 20 -year LOWESS-smoothed values. 

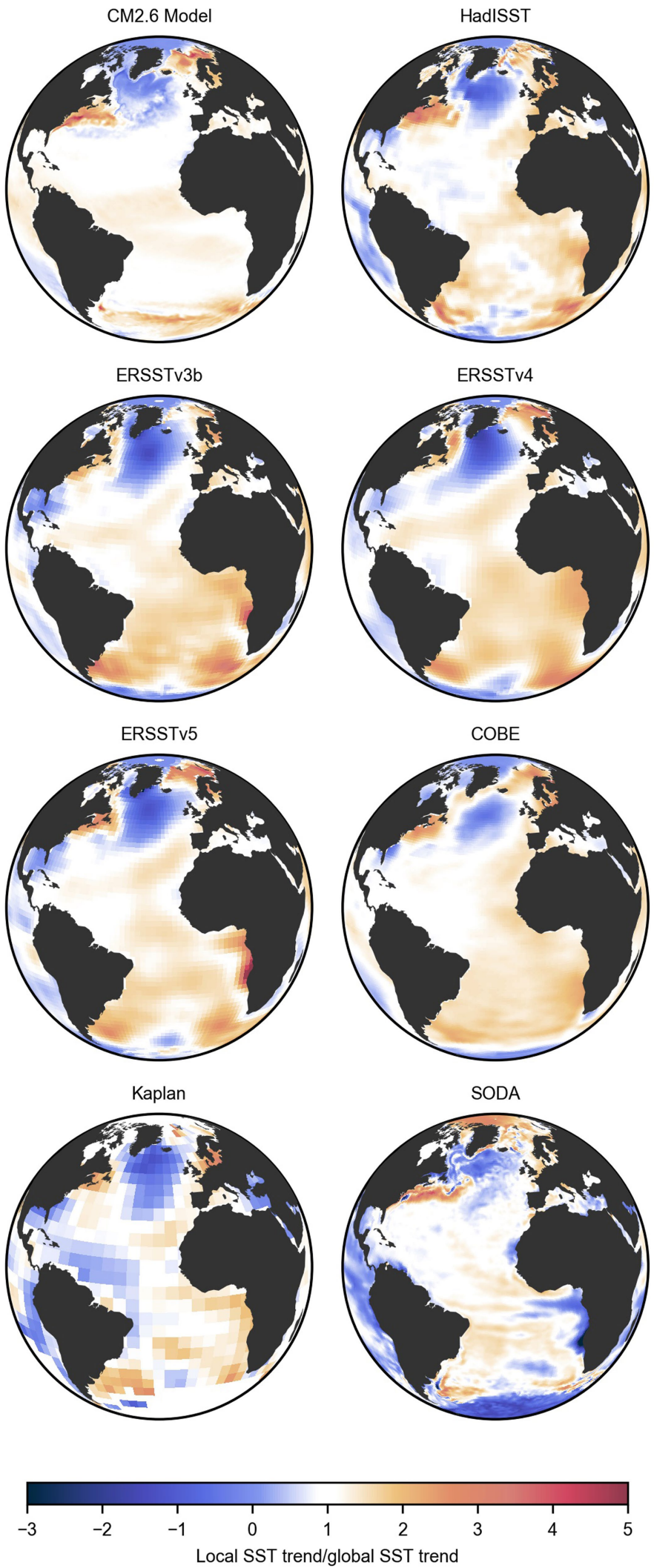

Extended Data Fig. 5 | Linear SST trends from a $\mathrm{CO}_{2}$-doubling experiment using the GFDL CM2.6 climate model, and observed long-term trends from different SST data products, normalized with the respective global mean SST trends. The trend from 1870 to 2016 was calculated using those datasets that provide data until the present $\left(\right.$ HadISST $^{16}$, ERSSTv5 ${ }^{54}$, ERSSTv $^{55}{ }^{55}$ ERSSTv $3 b^{56}$ and Kaplan ${ }^{57}$ ). Otherwise, it was calculated from 1870 to the end of the available time period (SODA ${ }^{58}$ and $\mathrm{COBE}^{59}$; see Extended Data Table 1). The SODA data are given for a depth of $5 \mathrm{~m}$ instead of the surface; thus, the long-term trend differs for regions with ice cover. For the SODA data, the normalization was adjusted with surface SST data instead of the data at a 5-m depth, to make this dataset comparable to the others. All datasets show a prominent cooling in the subpolar gyre region; the high-resolution data (HadISST, COBE and SODA) also show pronounced warming in the Gulf Stream region. 


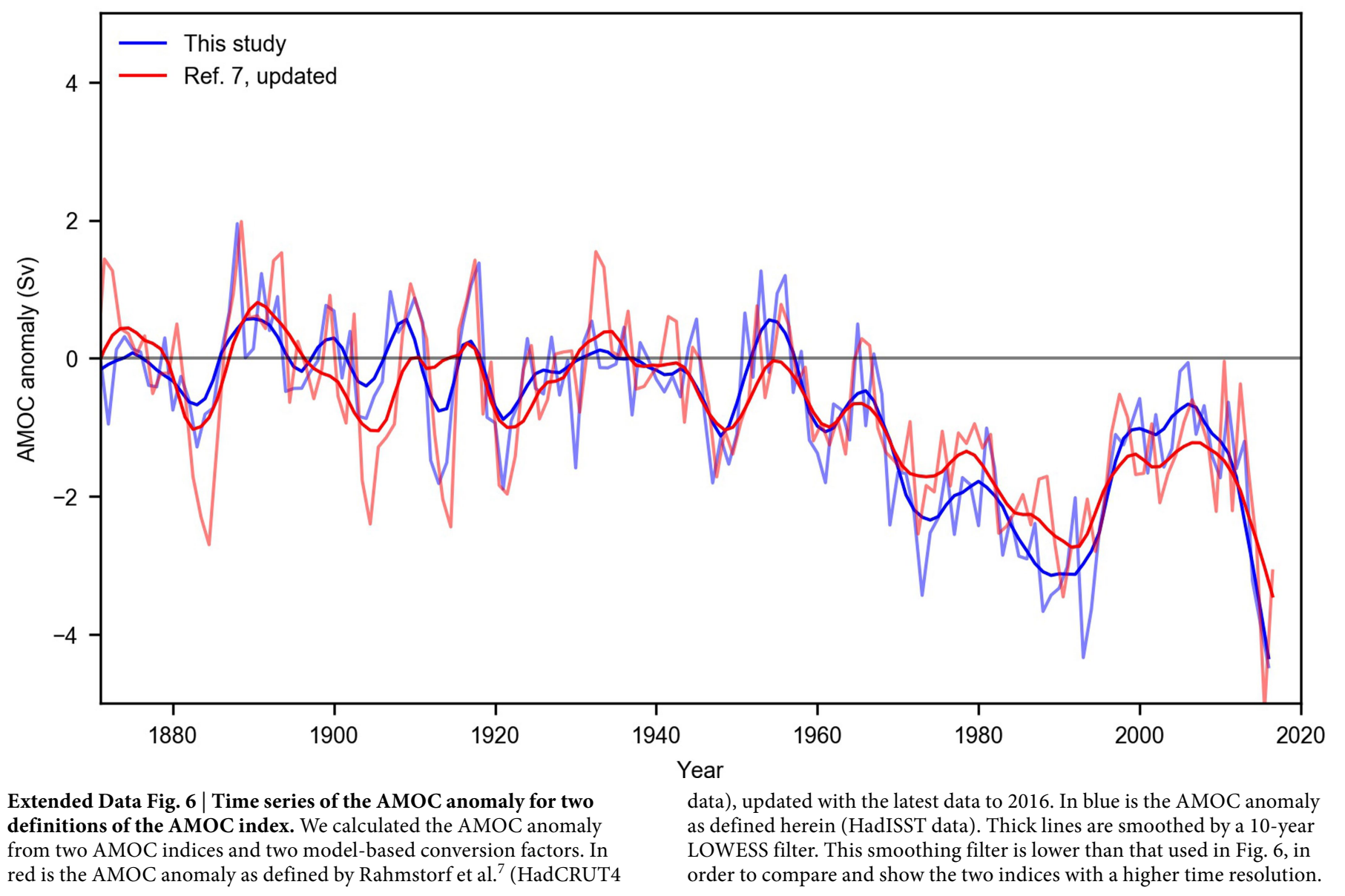



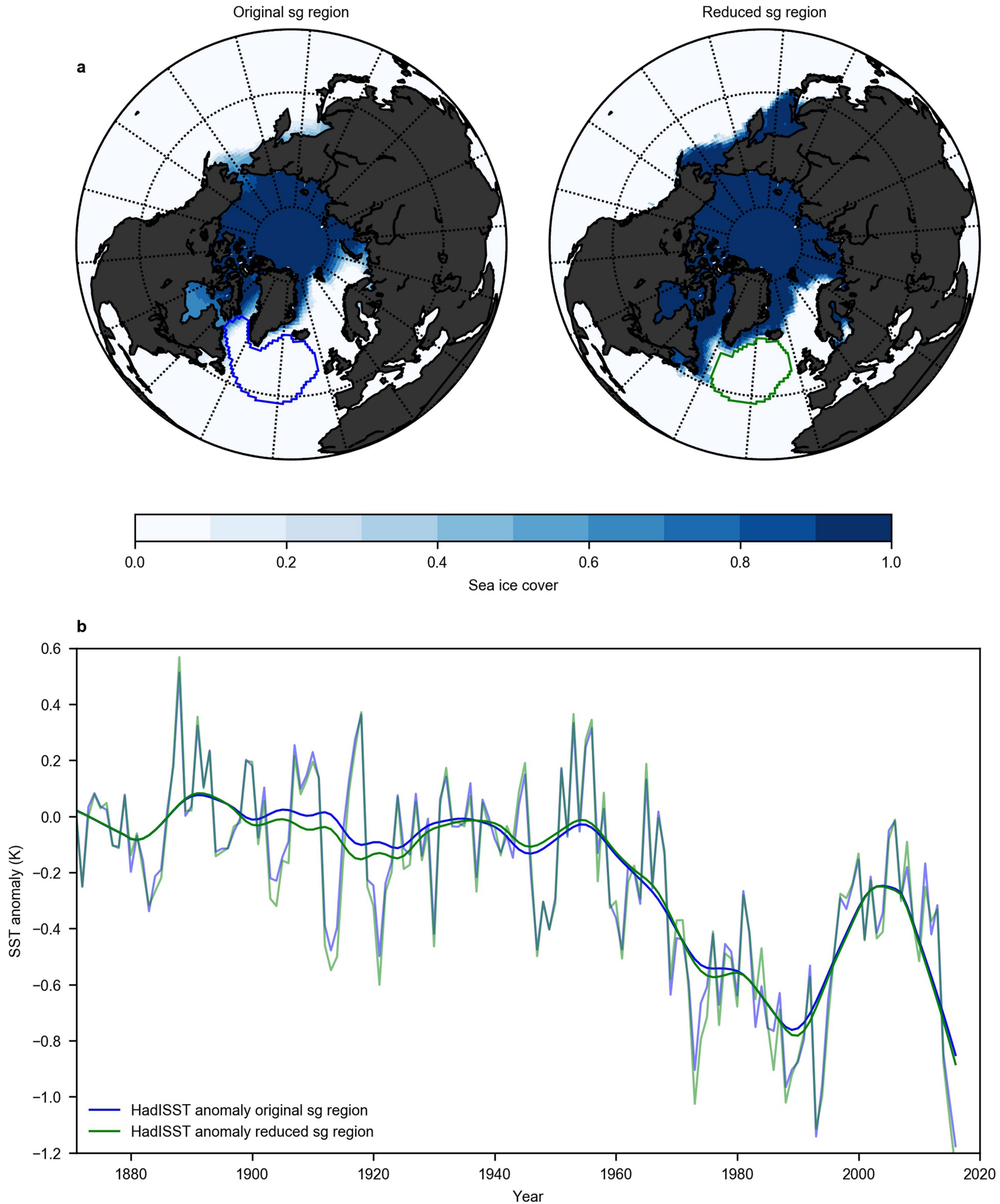

Extended Data Fig. 7 | Sensitivity to the extension of the subpolar gyre region regarding sea-ice cover. a, Left panel, our original subpolar gyre region (blue outline) and the average November-May sea-ice cover from 1870 to 2016 (blue shading, from HadISST data). Right panel, a reduced subpolar gyre region (green outline) that is always ice-free, compared with the maximum sea-ice cover for the November-May season from 1870 to 2016. b. Comparison of the AMOC indices based on these two regions. The thin lines show annual values, the thick lines show the 20 -year LOWESS-smoothed values. 

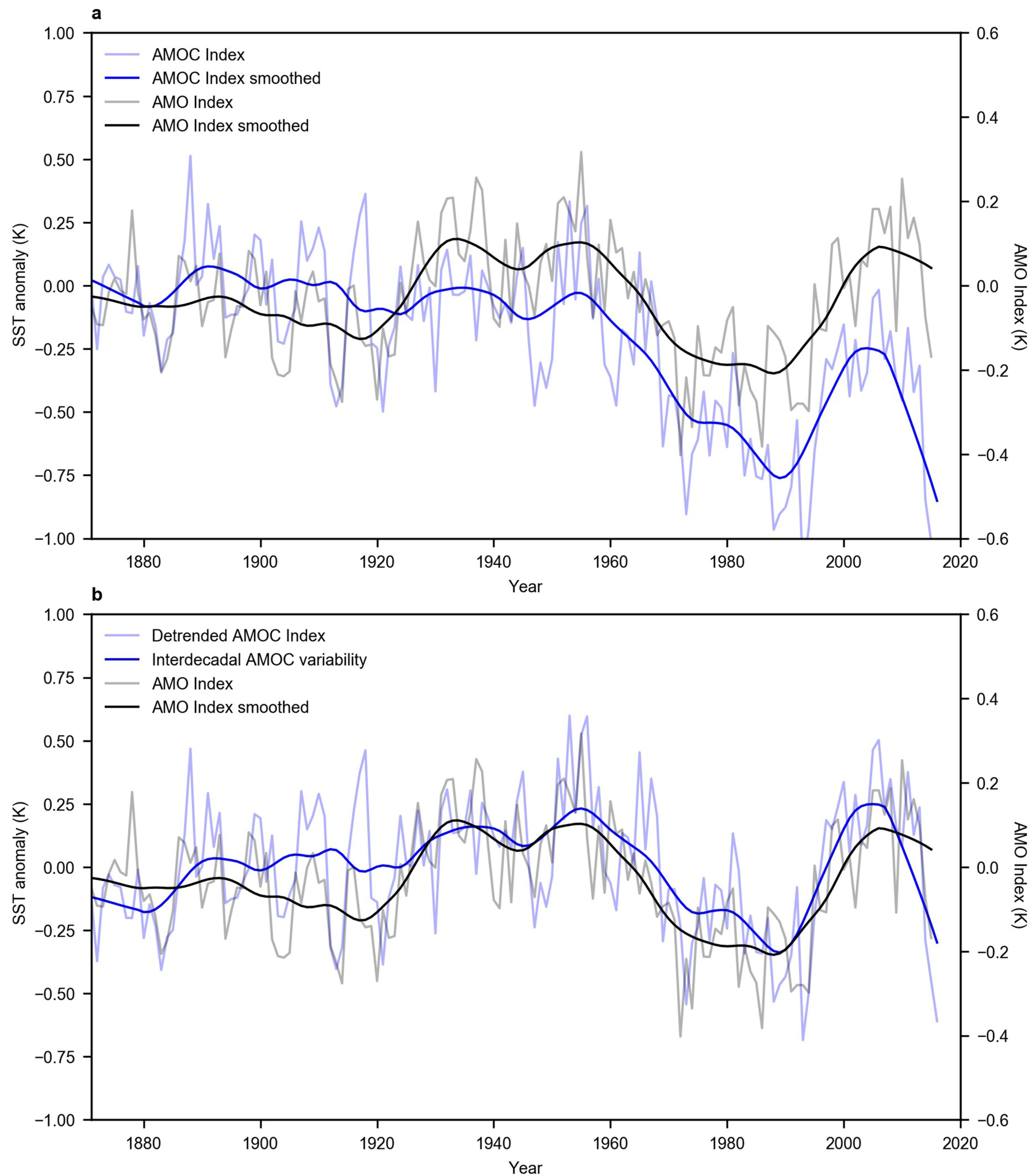

Extended Data Fig. 8 | Comparison of interdecadal variability of the AMOC index and the AMO index. a, We calculated the AMO index from the HadISST dataset after Trenberth and Shea ${ }^{60}$. This index is defined as the weighted mean SST over the North Atlantic $\left(0^{\circ} \mathrm{N}\right.$ to $\left.80^{\circ} \mathrm{N}\right)$, relative to the mean SST from the period 1901-1970, but with the global mean SST (averaged over the global oceans from $60^{\circ} \mathrm{S}$ to $60^{\circ} \mathrm{N}$ ) removed. The thin lines show annual values, the thick lines indicate the 20 -year LOWESS- smoothed values. We show our AMOC index for comparison. b, As for panel a, but here the AMO index is compared with the interdecadal variability of our AMOC index - that is, the detrended 20-year LOWESSsmoothed index. The comparison shows that the AMO index has similar interdecadal variability to the AMOC index but is lacking the climatic trend found in the latter. 

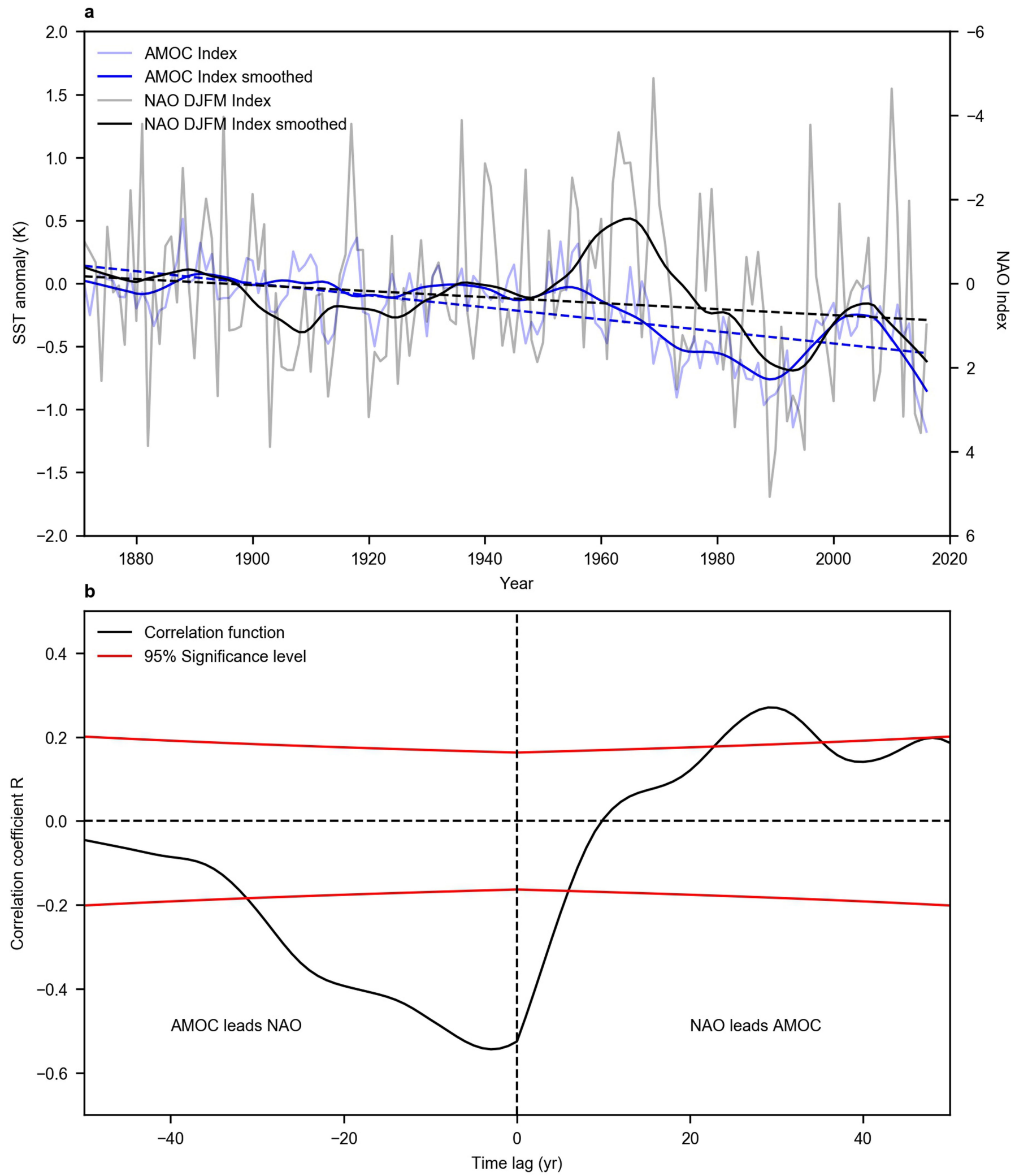

Extended Data Fig. 9 | Comparison of AMOC and NAO. a, Comparison of our AMOC index with the interdecadal variability in the NAO index (after Hurrell ${ }^{61}$ ), calculated as the sea-level pressure at the Lisbon station minus the sea-level pressure at the Stykkisholmur/Reykjavik station for the months December to March (DJFM). The thin lines show annual values, the thick lines show the 20-year LOWESS-smoothed values. The linear trend over the whole time period is shown with dashed lines. b, Lagged cross-correlation between the AMOC index and the NAO index shows that peak negative correlation occurs when the AMOC leads the NAO by three years, with $R=-0.54$. The red lines mark the $95 \%$ significance level. 
Extended Data Table 1 | Detailed data and model information

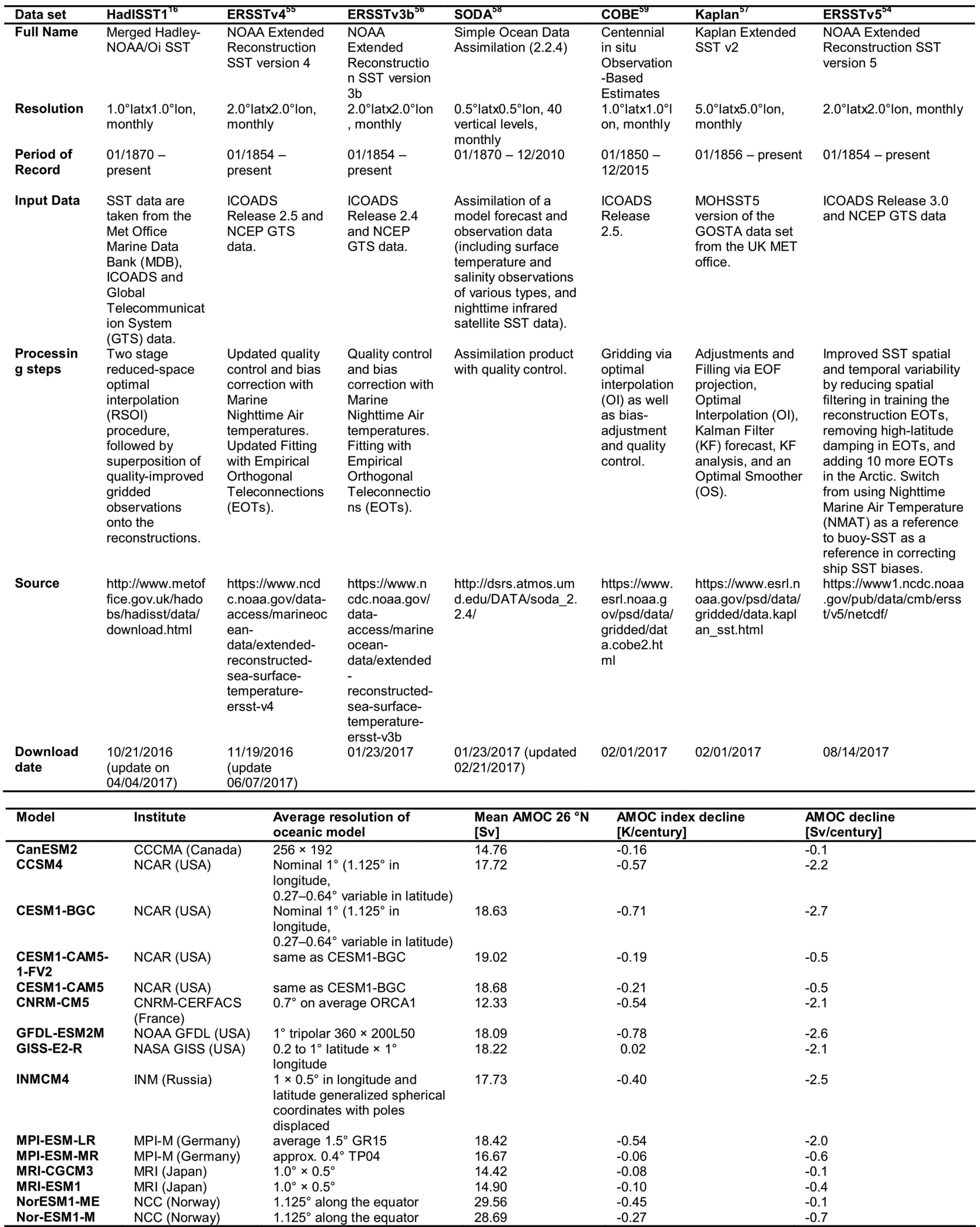

Overview of the spatial and temporal resolution, period of record, input data, processing steps and sources of the 7 datasets that we used to study the AMOC slowdown, as well as details of the 15 CMIP5 models used (for more detail, see Table 9.A.1. of ref. ${ }^{62}$ ). 